\title{
ARTÍCULOS
}

\section{DISQUISICIÓN SOBRE EL PILOTO EN LA EDAD MODERNA. CIELO Y MAR.}

\author{
Gabriel Pintos Amengual \\ Universidad del País Vasco \\ mallorca1954@hotmail.com
}

\begin{abstract}
Resumen: En este artículo nos adentramos en la figura del piloto en la Edad Moderna, etapa en donde transcurrió el paso del arte de navegar a la navegación astronómica científica. En donde el piloto fue una figura clave en la gran transformación que sufrió la navegación marítima en ese periodo tan importante de la historia de la ciencia, pasando en su profesión del conocimiento intuitivo, al empírico y finalmente al especulativo. Para ello, se abordan el estamento de procedencia, las competencias técnicas que debía reunir en el ejercicio de la profesión, así como su consideración técnica. Finalmente presentamos como el estamento social al que pertenecía, condicionó su desarrollo social, profesional y técnico.
\end{abstract}

Palabras clave: Piloto, transición a la navegación astronómica científica, estamento social, Ordenanzas de la Armada de 1748, Ordenanzas del Colegio de San Telmo de Sevilla de 1786, Plan Winthuysen de 1790.

Tittle: DISQUISITION ABOUT THE PILOTO IN THE MODERN AGE. SKY AND SEA.

Abstract: In this article, we examine the figure of the Piloto in the Modern Age, the period in which took place the swap from sailing as a flair to the scientific and astronomical navigation. At such a very important time in the history of science, The Piloto had an essential role in the great transformation suffered by maritime navigation. Navigational knowledge, formerly based on the intuition, moved first to the empiric knowledge and finally to the speculative, what implied a step forward in his career. To this end, in the abstract, it is tackled his initial social status, the technical capabilities he should hold to develop his job, as well as his technical consideration. Eventually, we show how the social condition which he belonged to, determined his social, professional and technical development.

Keywords: Piloto, move to the scientific and astronomical navigation, social condition, Ordenanzas de la Armada of 1748, Ordenanzas del Colegio de San Telmo de Sevilla of 1786, Plan Winthuysen of 1790.

\section{Introducción}

Durante la Edad Moderna transcurrió el paso del arte de navegar a la navegación astronómica científica, en el que intervinieron factores como la aplicación de las correcciones a las alturas observadas, la trigonometría esférica, la utilización de los logaritmos, así como la de los instrumentos de reflexión para tomar alturas y

Recibido: 27-04-2021

Aceptado: $13-05-2021$

Cómo citar este artículo: PINTOS AMENGUAL, Gabriel. Disquisición sobre el piloto en la Edad Moderna. Cielo y mar. Naveg@mérica. Revista electrónica editada por la Asociación Española de Americanistas [en línea]. 2021, n. 27. Disponible en: <http://revistas.um.es/navegamerica>. [Consulta: Fecha de consulta]. ISSN 1989-211X. 
la determinación de la longitud por distancias lunares y por cronómetros. El principal agente transmisor para poner en práctica en la mar los adelantos que se iban haciendo en ese campo aplicado a la navegación fue el piloto. En consecuencia, estos avances determinaron el curso de su desarrollo científico.

Existen profusión de estudios sobre la Carrera de Indias, la vida cotidiana del hombre de mar, los naufragios, los peligros del océano, los pilotos y la formación que recibieron en una época determinada, el estamento al que pertenecían, pero no hemos encontrado ninguno que estudie la figura del piloto en la Edad Moderna en su aspecto social, técnico y profesional. Por lo que la importancia de este artículo radica en analizar la evolución que experimentaron los pilotos de la Carrera de Indias en los social, lo técnico y lo profesional a lo largo de la Edad Moderna.

El objetivo de este trabajo consiste en: Describir la evolución profesional del piloto y contrastar si el estamento del que procedía fue determinante para su desarrollo social, profesional y técnico.

Partimos de la figura del piloto a través de las distintas denominaciones que ha recibido a lo largo de la historia y cómo afectaron a las atribuciones profesionales que llevaban aparejadas. Así mismo, se analizan las competencias técnicas que este profesional debe reunir para el ejercicio de la profesión, así como la regulación del título que se le expide para este fin. Por último, se atiende la faceta social y técnica ya que el estamento de procedencia del piloto marcó sus posibilidades de evolución no solo social, sino también profesional y técnica.

\section{La figura del piloto}

Desde tiempos pretéritos, el piloto ha sido el técnico náutico encargado de la derrota del buque. A estos profesionales encargados de dirigir la nave, se les ha denominado con diferentes nombres a través de la historia, como: naucher, marinero o piloto ${ }^{1}$. Además de a través de las distintas denominaciones que ha recibido, nos podemos aproximar a la figura del piloto por medio de la selección de definiciones que se recogen en la tabla 1.

\footnotetext{
1 Véanse: LÓPEZ, Gregorio. Las siete partidas del Rey Don Alfonso el Sabio. Cotejada por el Lic. Gregorio López. Vol. 2. Segunda y Tercera partida. París: Lecointe y Laserre, 1843, p. 285; LULL, Ramón. Arbol de la ciencia de el muy iluminado maestro Raymvndo Lvlio: nuevamente traducido y explicado por el Teniente de Maestro de Campo General Don Alonso de Zepeda y Adrada, Governador de el Thol-huys. Bruselas: Francisco Foppens, Impresor y mercader de libros, 1663, p.100; CAPMANY Y DE MONPALAU, Antonio. Código de las costumbres marítimas de Barcelona, hasta aquí vulgarmente llamado libro del consulado. Madrid: Imprenta de Don Antonio Sancha, 1791, pp. 32-33.
} 


\begin{tabular}{|l|l|}
\hline \multicolumn{1}{|c|}{ Rutor } & \multicolumn{1}{c|}{ Relación de definiciones de piloto } \\
\hline $\begin{array}{l}\text { García de } \\
\text { Palacio (1587) }\end{array}$ & $\begin{array}{l}\text { "el que tiene a su cargo el govierno del navío, desde que se hace a la } \\
\text { vela para algún viaje, hasta que surge, y en eso le obedecen todos los } \\
\text { marineros"2. }\end{array}$ \\
\hline $\begin{array}{l}\text { Enciclopedia } \\
\text { General del Mar } \\
\text { (1992) }\end{array}$ & $\begin{array}{l}\text { "(del it. Piloto; éste del ant. pedotto, y éste a su vez del gr. pedon, } \\
\text { gobernalle) El que entiende y ejerce el arte de dirigir un buque } \\
\text { determinando su situación y los rumbos que debe seguir para trasladarse } \\
\text { al punto de su destino"3. }\end{array}$ \\
\hline Vigier (1969) & $\begin{array}{l}\text { "Se entiende por Piloto el oficial náutico que, con capacidad legal y en } \\
\text { posesión del correspondiente título profesional, presta sus servicios a } \\
\text { bordo de los buques mercantes bajo las órdenes de su Capitán, al que } \\
\text { auxilia en sus funciones y sustituye en determinados casos [...] En } \\
\text { tiempos pretéritos era un técnico náutico encargado de la derrota de la } \\
\text { nave, cuyo Capitán, por carecer frecuentemente de aptitud profesional, } \\
\text { se limitaba al desempeño de funciones administrativas y comerciales por } \\
\text { cuenta del armador". }\end{array}$ \\
\hline
\end{tabular}

Tabla 1: Relación de definiciones de piloto. Fuente: Elaboración propia, a partir de las referencias seleccionadas.

De lo expuesto se puede deducir que, el piloto es el encargado del gobierno del buque, para lo cual necesita tener unos conocimientos técnicos, acreditados por la posesión de un título profesional, así como disponer de los instrumentos náuticos adecuados para la determinación de la situación del buque, de forma que pueda navegar de un punto a otro con seguridad. La posesión de una acreditación profesional oficial, para ejercer de piloto, no siempre fue necesario, como veremos en el epígrafe siguiente, en donde trataremos la regulación de la profesión de piloto.

\section{Regulación de la profesión de piloto en la Edad Moderna}

El empleo con mayor cualificación técnica a bordo secularmente había sido el piloto, a cargo de quien estaba la navegación. Su trabajo fundamental consistía en hacerse cargo del timón y "echar el punto". También existía la figura del maestre, a quien, como veremos más adelante, para el ejercicio de su profesión se le requería una preparación técnica equiparable a la del piloto. No obstante, la titulación de piloto se consideraba superior a la del maestre excepto en lo referente a los aspectos comerciales ${ }^{5}$. Se les denominó maestres de navíos porque no sólo debían saber de pilotaje sino de todo lo concerniente al aparejo, avituallamiento y tripulación del buque ${ }^{6}$. Las dudas sobre este punto quedaron aclaradas, al plantear la Universidad de Mareantes si los pilotos examinados, se tenían que examinar para

\footnotetext{
2 GARCIA DE PALACIO, Diego. Instrucción náutica, para el buen uso, y regimiento de las naos, su traza, y gobierno conforme a la altura de México. México: En casa de Pedro Ocharte, 1587, fol. 151.

${ }^{3}$ Enciclopedia General del Mar. Barcelona: Ediciones Garriga, 1992, p. 1.267.

4 VIGIER DE TORRES, Agustín. Curso de Derecho Marítimo. Madrid: Subsecretaría de la Marina Mercante, 1969, p. 449.

${ }^{5}$ NAVARRO GARCÍA, Luis. Pilotos, maestres y señores de naos en la carrera de las Indias. Revista histórica, literaria y artística. 1967, vol. 46, n. 141, pp. 241-298.

${ }^{6}$ VEITIA LINAJE, José. Norte de la Casa de Contratación de las Indias Occidentales. Sevilla: Juan Francisco de Blas, 1672.
} 
ser maestres, quedando resuelta la cuestión con una Real Cédula de $1573^{7}$.

Establecida la figura del piloto y la relación existente entre este y el maestre, nos adentramos en la regulación de la profesión de piloto. Se considera que una profesión está regulada cuando su acceso y ejercicio vienen determinados por la posesión de una determinada cualificación profesional, sancionada por la Administración Pública mediante el otorgamiento de un título. La regulación de las profesiones relacionadas con la actividad científica en España data de 1477, con la creación del Tribunal Protomedicato, cuya finalidad era controlar el ejercicio de la medicina. Así, entre las primeras profesiones reguladas encontramos a los médicos, que debían cursar estudios universitarios y a los cirujanos, que carecían de enseñanza reglada. A estos se unieron los empíricos cuando, mediante la pragmática de 1500 de los Reyes Católicos, se autorizó para ejercer como cirujanos a barberos y sangradores. Los boticarios tenían una situación parecida a la de los cirujanos. También el ejercicio de la albeitería estuvo reglamentado por una pragmática de 1500 de los Reyes Católicos, bajo el Tribunal Protoalbeirato. Los pilotos se unieron a este grupo de profesiones reguladas, cuando en 1508 se promulgó la instrucción para graduar pilotos, que describiremos más adelante. Así, se puede concluir que, en la España del siglo XVI, las profesiones reguladas, relacionadas con la ciencia eran: médicos, cirujanos, boticarios, albéitares y pilotos ${ }^{8}$.

La regulación de los pilotos se inició en 1508 al instituir la figura del piloto mayor ${ }^{9}$ dentro de la Casa de la Contratación de Sevilla ${ }^{10}$.

Los viajes realizados al nuevo mundo, en los años transcurridos desde el descubrimiento, pusieron de manifiesto, que la preparación de los pilotos no era la

\footnotetext{
7 La Real Cédula dada en San Lorenzo el Real en 15 de junio de 1573 "[...] porque el piloto siendo examinado no tenía necesidad de lo ser de maestre por incluirse en el grado de piloto este otro, y ser aquel mayor [...]" (PULIDO RUBIO, José. El Piloto Mayor de la casa de Contratación de Sevilla. Pilotos mayores, catedráticos de cosmografía y cosmógrafos. Sevilla: Escuela de Estudios Hispano Americanos, 1950, p.160).

8 LÓPEZ PIÑERO, José María. Ciencia y técnica en la sociedad española de los siglos XVI y XVII. Barcelona: Labor, 1979, p. 52.

9 AGI, Indiferente, L.1, F.65V-67. AGI, Real Provisión a Américo Vespucio, piloto mayor, concediéndole facultad de examinar a los pilotos que hayan de ir a Indias, dándoles carta que los acredite como tales pilotos; y a los oficiales de la Casa de la Contratación para que hagan reunir a todos los pilotos más expertos y bajo la dirección de Américo Vespucio se reúnan los pilotos y rehagan el padrón general, dándole el nombre de padrón real. 1508-08-06, Valladolid.

10 Real Provisión de los Reyes Católicos ordenando establecer en Sevilla una Casa de la Contratación y promulgando las primeras Ordenanzas para su gobierno. Alcalá de Henares, 20 de enero de 1503. AGI, Patronato, 251, R.1. La casa de Contratación de Sevilla creada para, entre otras funciones, estimular, encauzar y controlar el tráfico marítimo con el nuevo mundo, rasgos entre otros, que constituyeron los orígenes del mercantilismo castellano. Con respecto al mercantilismo, Corona Baratech y Armillas Vicente en Historia General de España y América: La España de las Reformas Hasta el final del Reinado de Carlos IV. Volumen 10-2. Madrid: Rialp, 1990, señalan que hay dos manifestaciones de diferente signo: "Ramón Carande niega rotundamente que pueda atribuirse una política económica coherente a los gobernantes españoles del siglo XVI. En cambio, Earl J. Hamilton estima que antes de 1700 ya se habían adoptado en España todas las medidas de política económica mercantilista, salvo (y la excepción es importante) las reales fábricas y las compañías privilegiadas" (p. 20). Por su parte Vicens Vives en Historia Económica de España. Barcelona: Vicens-Vives, 1977, pp. 282-283, para establecer los orígenes del mercantilismo castellano referencia a Hamilton, situando su origen en la época de los Reyes Católicos.
} 
idónea para este tipo de travesías, como vino demostrado por los errores cometidos, que causaron pérdidas de vidas y bienes, por lo que para paliar este desconocimiento y sus efectos, no sólo para realizar los mencionados viajes sino también para los dirigidos a nuevas tierras que aún estaban por descubrir, se necesitaban profesionales mejor formados y más expertos, que pudiesen dirigir las naves e incluso dibujar los contornos de su costa. Para conseguir este objetivo, se estableció con carácter de obligatoriedad el aprobar el examen de piloto que facultaba para la Carrera de Indias y se prohibía que pudiesen dar viajes como pilotos, ni ser contratados como tales sin ser examinados por el piloto mayor.

Para poder realizar trayectos oceánicos, desde ese momento, fue requisito indispensable obtener el título de piloto de la Carrera de Indias. La mencionada Real Cédula, reflejaba en su parte inicial, como una verdadera exposición de motivos, especificando sobre las materias que debían ser instruidos y se les expidiese carta de examen, sin la cual no podrán ser contratados para realizar dichos viajes ${ }^{11}$. También establecía la posibilidad de que el piloto mayor, en caso de que faltasen pilotos examinados, pudiese habilitar por un tiempo determinado, a las personas que considerase más hábiles ${ }^{12}$.

El cargo de piloto mayor, ha sido considerado el primer puesto científico de la administración española, al que se le asignaron las siguientes funciones: formar y examinar a los pilotos de la Carrera de Indias, dibujar y corregir las cartas náuticas y mejorar y perfeccionar los instrumentos de navegación. Al introducir la figura del piloto mayor, la Casa de Contratación de Sevilla se convirtió en un órgano centralizador de la actividad náutica, considerado como el inicio de la reglamentación del título de piloto como técnico en el arte de navegar ${ }^{13}$.

El primero que fue designado para desempeñar el puesto fue Américo Vespucio (1454-1512), al que le siguieron Juan Díaz de Solís (1470-1516) y Sebastián Caboto (1477-1557) cerrando el círculo de pilotos mayores exploradores ${ }^{14}$. En la tabla 2, relacionamos las personas que ostentaron el cargo de piloto mayor de la Casa de Contratación de Sevilla.

A la figura del piloto mayor, se unieron las del cosmógrafo fabricador de instrumentos (1523) y la del catedrático de Cosmografía (1552) para leer la Cátedra de Navegación, cargos que pusieron al servicio de la Corona española sus saberes científicos y su experiencia en las navegaciones, a los que se hará referencia más adelante.

\footnotetext{
11 PULIDO RUBIO, José. EI Piloto Mayor... Op. cit., pp. 66-67.

12 FERNÁNDEZ DE NAVARRETE, Martín. Colección de los viages y descubrimientos que hicieron por mar los españoles desde fines del siglo XV. Vol. 3. Madrid: Imprenta Real, 1829, p. 300.

${ }^{13}$ LÓPEZ PIÑERO, José María. El Arte de Navegar en la España del Renacimiento. Barcelona: Labor, 1986, p. 128.

${ }^{14}$ PULIDO RUBIO, José. El Piloto Mayor... Op. cit., p. 539.
} 


\begin{tabular}{|c|l|c|}
\hline \multicolumn{3}{|c|}{ Pilotos mayores de la Casa de Contratación de Sevilla } \\
\hline Año nombramiento & \multicolumn{1}{|c|}{ Nombre y Apellidos } & Año cese \\
\hline 1508 & Américo Vespucio & 1512 \\
\hline 1512 & Juan Díaz de Solís & 1516 \\
\hline 1518 & Sebastián Caboto & 1548 \\
\hline 1552 & Alonso de Chaves & 1587 \\
\hline 1586 & Rodrigo Zamorano & 1596 \\
\hline 1596 & Andrés García de Céspedes & 1598 \\
\hline 1598 & Rodrigo Zamorano & 1620 \\
\hline 1620 & Diego Ramírez de Arellano & 1624 \\
\hline 1625 & Antonio Moreno & 1634 \\
\hline 1638 & Francisco de Ruesta & 1673 \\
\hline 1674 & Juan Cruzado de la Cruz y Mesa & 1692 \\
\hline 1692 & Alonso de Bacas Montoya & 1694 \\
\hline 1695 & Francisco Antonio de Orbe & 1717 \\
\hline
\end{tabular}

Tabla 2: Pilotos mayores de la Casa de Contratación de Sevilla. Fuente: Elaboración propia, con información recogida de Pulido Rubio ${ }^{15}$.

Los requisitos necesarios para conseguir el título de piloto se modificaron por Real Cédula de 2 de agosto de $1527^{16}$ estableciendo los siguientes:

- Ser natural de los reinos de Castilla.

- Haber navegado seis años como mínimo a las Indias, que tenían que probar mediante testigos o escrituras y haber estado en la Isla Española, Cuba, Tierra Firme y Nueva España.

- Tener carta de marear y saber echar el punto en ella, así como conocer los puntos de destinos y los rumbos.

- Tener astrolabio y cuadrante.

- Los conocimientos náuticos que debían conocer los pilotos.

- Realizar examen, en el que tenían que presentar astrolabio, cuadrante, carta de marear y regimiento.

Estos requisitos se extendieron a los maestres, quedando obligados a su cumplimiento por Real Cédula de 21 de mayo de 1534, siendo preceptivo para poder ejercer la profesión ${ }^{17}$. El requisito de nacionalidad para desempeñar los cargos de piloto y maestre estuvo vigente hasta la emisión de la Real Cédula de 2 de agosto de 1547, que permitía el ejercicio de la profesión a los extranjeros casados, con residencia familiar en España y en el caso de los solteros debían obtener carta de naturaleza antes de realizar el examen ${ }^{18}$.

15 PULIDO RUBIO, José. El Piloto Mayor... Op. cit.

${ }^{16}$ Real Cédula a Sebastián Caboto, piloto mayor, sobre las órdenes que ha de guardar en el examen de los pilotos de Indias (10 capítulos). 1527-8-2 Valladolid. AGI, Indiferente, 421, L.12, F.185V-187R.

17 PULIDO RUBIO, José. El Piloto Mayor... Op. cit., pp. 57-58.

18 Véanse: FERNÁNDEZ DURO, Cesáreo. Disquisiciones Náuticas. Arca de Noé. Vol. 6. Madrid: Imprenta, Estereotipia y Galvanoplastia de Aribau y C. Sucesores de Rivadeneyra, 1881; MARTíNMERÁS, Luisa. Las enseñanzas náuticas en la Casa de la Contratación de Sevilla. En: ACOSTA, A.; GONZÁLEZ, A. y VILA, E. (coords.). La Casa de la Contratación y la navegación entre España y las Indias. Sevilla: Universidad de Sevilla; CSIC; Fundación el Monte, 2004, pp. 667-693. 
Tras ser examinados y aprobados por el piloto mayor de la Casa de Contratación, pilotos y maestres conseguían el permiso para hacer la Carrera de Indias, quedando ligados a ésta por contrato por el que se comprometían a la confidencialidad de rutas, cartografía y conocimientos de navegación, así como a la recopilación de datos náuticos en sus viajes. Antes de partir estaban obligados a mostrar sus cartas, instrumentos (astrolabio y agujas) y regimientos de navegación para recibir el visto bueno del piloto mayor de la Casa de Contratación, lo que acabó dando lugar a un lucrativo negocio que ocasionó no pocas disputas, que han sido recogidas y analizadas por distintos autores, desde Cesáreo Fernández Duro a Luisa Martín-Merás.

Transcurridos 44 años de la creación del cargo de piloto mayor, para formar y examinar a los pilotos de la Carrera de Indias, se creó el cargo de catedrático de Cosmografía para el que se nombró al bachiller Gerónimo Chaves ${ }^{19}$, por medio de la Real cédula de 4 de diciembre de $1552^{20}$.

Los requisitos necesarios para conseguir el título de piloto cada vez fueron más exigentes, por la pérdida de buques y vidas humanas en la mar, inconvenientes atribuidos a la deficiente formación de los pilotos de la Carrera de Indias. Persistía así el problema que, en 1508, había motivado que se facultara al piloto mayor para formar y examinar a los pilotos ${ }^{21}$. Para paliar la situación motivada por los errores de los pilotos se instituyeron en 1552 una serie de medidas, entre las que destacaron: Separación del piloto mayor de la formación de los pilotos, creación del cargo de catedrático de Cosmografía, impartición de la lectura de la Cátedra en el seno de la Casa de Contratación, fijación de la duración de la formación de los pilotos, en un año, con establecimiento de un calendario escolar y la ampliación del programa formativo.

Con la creación de la Cátedra de Cosmografía y la elección para el cargo del bachiller Gerónimo Chaves, se optó por un perfil científico-técnico, frente al perfil práctico de los pilotos mayores, que hasta ese instante se habían encargado de la formación de los pilotos y así se continuó en los sucesivos nombramientos, que recayeron en los componentes de la tabla 3.

\footnotetext{
${ }^{19}$ Nombramiento de Jerónimo de Chaves como cosmógrafo y catedrático de Cosmografía de la Casa de la Contratación. 1552-12-4 Monzón. AGI. Contratación, 5784, L.1, F.95-95V.

20 PULIDO RUBIO, José. EI Piloto Mayor... Op. cit., pp. 72-73.

${ }^{21}$ PÉREZ-MALLAÍNA BUENO, Pablo Emilio. Naufragios en la Carrera de Indias durante los siglos XVI y XVII. El hombre frente al mar. Sevilla: Universidad de Sevilla, 2015, p. 67, señala que investigaciones realizadas tras los naufragios de los navíos de la Carrera de Indias mostraron que los motivos que con mayor frecuencia causaron estos 'inconvenientes' fueron: la sobrecarga de los buques, deficiencias en las carenas, falta de tripulantes expertos, errores de los pilotos y el estado de la mar, mientras que CÉSPEDES DEL CASTILLO, Guillermo. La defensa de América. En: RUIZ MARTíN, F. La monarquía de Felipe II. Madrid: Real Academia de la Historia, 2003, pp. 381-412, asegura que la Carrera de Indias destacó por su seguridad, soportado por la estimación realizada por García Baquero sobre datos de Chaunu, en la que la pérdida de buques que efectuaban la Carrera de Indias se situó en torno al 3\% entre 1546 y 1650 . Señala este autor que un $80 \%$ de los naufragios se debieron al estado de la mar y errores de navegación y un $20 \%$ tuvieron lugar como resultado de ataques enemigos (piratas, corsarios y acciones de guerra).
} 


\begin{tabular}{|c|c|c|}
\hline \multicolumn{3}{|c|}{ Catedráticos de Cosmografía y Navegación de la Casa de Contratación de Sevilla } \\
\hline Año nombramiento & Nombre y Apellidos & Año cese \\
\hline 1552 & Gerónimo de Chaves & 1568 \\
\hline 1569 & Sancho Gutiérrez & 1574 \\
\hline 1573 & Diego Ruiz & -- \\
\hline 1575 & Rodrigo Zamorano & 1613 \\
\hline 1612 & Antonio Moreno & -- \\
\hline 1635 & Lucas Guillén de Veas & 1639 \\
\hline 1636 & Rodrigo Zamorano de Oceta & -- \\
\hline 1645 & Francisco de Ruesta & -- \\
\hline 1645 & Diego Ramírez de Arellano & -- \\
\hline 1658 & Juan de Saavedra & 1666 \\
\hline 1668 & Alonso de Bacas Montoya & 1707 \\
\hline 1707 & Francisco Antonio de Orbe & -- \\
\hline
\end{tabular}

Tabla 3: Catedráticos de Cosmografía y Navegación de la Casa de Contratación de Sevilla. Fuente: Elaboración propia, a partir de información recogida de Pulido Rubio ${ }^{22}$.

La Real Cédula de 4 de diciembre de 1552, institucionalizó la obligación de asistir a la lectura de cosmografía y arte de navegar en la Casa de la Contratación de Sevilla, siendo el tiempo establecido de un año. Este año de formación, se redujo a tres meses, a instancias de Gerónimo Chaves. En solicitud dirigida al Rey, Chaves argumentaba que los conocimientos que él enseña pueden ser aprendidos en tres meses y que los que tenían que asistir a la lectura era gente pobre, que no tenían medios suficientes para poder subsistir este tiempo ${ }^{23}$. Esta petición fue concedida por Real cédula de 3 de junio de 1555. La obligación de asistir un año a la lectura de la Cátedra fue según Salavert Fabiani, una acción ineficaz ${ }^{24}$.

Más tarde, se modificó de nuevo por Reales Cédulas de 6 de octubre de 1567 estableciendo el periodo de formación en 2 meses y por la de 25 de febrero de 1568 se mantuvo el periodo de 2 meses para oír la lectura de la Cátedra, pero en el cómputo se incluyeron los festivos ${ }^{25}$.

A pesar de la obligatoriedad de asistir a la lectura de la Cátedra de Cosmografía, para poder examinarse de piloto, no siempre se cumplió y durante todo el periodo que estuvo vigente, se autorizaron dispensas, eximiendo de la asistencia a clase, permitiendo el examen a aquellos que demostraban experiencia en la navegación ${ }^{26}$.

Parece incomprensible, que pese a lo amplio del programa diseñado y el fin para el que se ideó, el propio Gerónimo Chaves recomendara la reducción del tiempo de lectura. Tampoco se comprende que, además, se estableciese que a los que tenían

22 PULIDO RUBIO, José. El Piloto Mayor... Op. cit.

23 PULIDO RUBIO, José. El Piloto Mayor... Op. cit., pp. 80-81; MEDINA, José Toribio. El Veneciano Sebastián Caboto al servicio de España. Vol. 1: Texto. Santiago de Chile: Imprenta y Encuadernación Universitaria, 1908, pp. 305-306.

${ }^{24}$ SALAVERT FABIANI, Vicent Lluis. La cultura científico técnica en la España de los siglos XVI y XVII. Bulletin Hispanique. 1995, vol. 97, n. 1, p. 239.

25 VEITIA LINAJE, José. Norte de la Casa de Contratación... Op. cit., p. 145. Anónimo. Recopilación de las leyes de los Reinos de las Indias, mandada imprimir y publicar por la Magestad Católica del Rey Don Carlos II, Nuestro Señor. Vol. III. Madrid: Boix, 1841, p. 305.

${ }^{26}$ PULIDO RUBIO, José. El Piloto Mayor... Op. cit., pp. 153-154. 
que examinarse de pilotos les bastaba saber leer el regimiento y firmar sus nombres ${ }^{27}$.

Los preceptos que atañen a la regulación del título de piloto se recogen en las Ordenanzas de la Casa de la Contratación de 1553. Los temas que contemplan estas ordenanzas se indican en la tabla 4. En ellas se especificaban aspectos tales como: lugar de realización del examen, composición del tribunal, expedición del título; el conocimiento teórico y práctico de la navegación antes de realizar el examen, quien efectuaba el examen, los componentes del tribunal, requisitos de nacionalidad, edad mínima, buena conducta, periodo navegado, examen para cada derrota; requisitos para volver a ser examinado en caso de ser reprobado, obligatoriedad de tener el título de piloto/maestre en cada caso, para poder ejercer la profesión ${ }^{28}$.

\begin{tabular}{|c|l|}
\hline \multicolumn{2}{|c|}{ Ordenanzas de la Casa de la Contratación (1553) que atañen a la regulación del } \\
piloto
\end{tabular}

Tabla 4: Ordenanzas de la Casa de la Contratación (1553) que atañen a la regulación del piloto. Fuente: Elaboración propia, con información extraída de Lyra30.

Conviene señalar en este punto que las Ordenanzas de 1553 regulaban otros aspectos como los referentes al control del tráfico marítimo, al apresto y organización de las flotas, al depósito de los caudales del Rey y de particulares, el control de la emigración a Indias, a la confección del padrón real y a la formación de los pilotos.

De una forma paralela a la reglamentación de las titulaciones del personal que tenía la dirección técnica de la nave en la Carrera de Indias, por medio de las Ordenanzas de la Casa de Contratación de Sevilla de 1553 se reguló la capacidad mínima que debían tener las naves (100 toneles) y la obligación de navegar en flota, así como la artillería y la tripulación con que debían estar dotadas (véase tabla 5).

\footnotetext{
27 Anónimo. Recopilación... Op. cit., vol. 3, p. 305.

28 LYRA, Francisco de. Ordenanzas Reales para la Casa de Contratación de Sevilla y para otras cofas de las Indias, y de la navegación, y contratación de ellas. Sevilla, 1647.

29 Refleja el 139 cuando por orden le corresponde el 135.

30 LYRA, Francisco de. Ordenanzas Reales... Op. cit.
} 


\begin{tabular}{|c|c|c|c|c|c|}
\hline \multicolumn{6}{|c|}{ Tripulaciones en función de la capacidad de las naves en toneles } \\
\hline $\begin{array}{c}\text { Capacidad de la nave } \\
\text { (toneles) }\end{array}$ & $\begin{array}{c}\text { Maestres } \\
\text { y Pilotos }\end{array}$ & Marineros & Lombarderos & Grumetes & Pajes \\
\hline 100 a 170 & 2 & 16 & 2 & 8 & 2 \\
\hline 170 a 220 & 2 & 28 & 4 & 2 & 4 \\
\hline 220 a 270 & 3 & 35 & 6 & 15 & 5 \\
\hline
\end{tabular}

Tabla 5: Tripulaciones en función de la capacidad de las naves en toneles. Fuente: Elaboración propia a partir de (Ordenanzas 1553, fo. xli-xliii).

Volviendo a la regulación del título de piloto, mientras la Casa de Contratación permaneció en Sevilla, las condiciones para obtener el título de piloto no variaron. Los cambios, se materializaron en 1748 , e iniciaron a partir de la llegada a España de la dinastía borbónica en 1700. El 28 de enero de 1717, el Rey Felipe V nombró a José Patiño Rosales (1666-1736) intendente general de la Marina y del Ejército de España y presidente del Tribunal de la Casa de Contratación de Indias. El recién nombrado intendente general, creó la Real Compañía de Guardiamarinas el 15 de abril de 1717, nombrando director a Francisco Antonio Orbe que ejercía el cargo de piloto mayor desde 1707, continuando en sus funciones de examinar a los pilotos y el 12 de mayo del mismo año por decreto de Felipe $V$ se trasladó la casa de contratación de Indias de Sevilla a Cádiz. Estos hechos propiciaron las transformaciones sufridas por la Casa de Contratación de Indias y que algunas de las funciones realizadas en su seno pasasen a desempeñarse en la Real Academia de Guardiamarinas, por lo que se considera a la Armada, como la continuadora de la labor científica que se realizó durante siglos en la Casa de Contratación de las Indias ${ }^{31}$.

La normativa reguladora de 1552 para la profesión de piloto continuó vigente hasta las Ordenanzas Generales de la Armada de 1748 (en adelante OGA, 1748), a través de su articulado se creó el Cuerpo de Pilotos de la Armada, en las que se establecieron tres clases de pilotos -primeros, segundos y ayudantes o pilotines-, para su formación se crearon las Escuelas Departamentales de Navegación en Cádiz, Ferrol y Cartagena y de forma sucinta se determinó cómo debía ser su formación, en la que para el acceso establecía que los aspirantes supiesen leer y escribir. Los que pretendían plaza de piloto eran examinados por el piloto mayor de la Armada, con asistencia de sus ayudantes o de otros dos pilotos hábiles. El examen versaba sobre los puntos esenciales del Arte de Navegar y uso de los instrumentos precisos para su práctica. Los candidatos declarados aptos se consignaban en certificación firmada por el piloto mayor y por los ayudantes o los pilotos que hubiesen asistido, con la expresión con la cual debían ser admitidos. Poseer esta certificación se estableció como obligatorio para todos aquellos que quisieran conseguir plaza como pilotos en navíos particulares, con lo que, a partir de este momento, quedaban también obligados a examinarse en las Escuelas Departamentales de Navegación ${ }^{32}$.

\footnotetext{
${ }^{31}$ CARAVACA DE COCA, José María. Apuntes para la historia de la Academia de la Real compañía de Guardias Marinas en sus momentos iniciales en Cádiz como continuadora de la labor científica de la Casa de la Contratación. Revista General de Marina. 2015, n. 269, pp. 877-891.

32 Ordenanzas Generales de la Armada. Vol. 1. Madrid: Imprenta de Juan Zuñigam, 1748, p. 166.
} 
En consecuencia, las atribuciones que tenía la Casa de Contratación en cuanto a exámenes y expedición de títulos de piloto pasaron a la Armada. Por lo que los alumnos del Real Colegio Seminario de San Telmo de Sevilla, así como los de las Escuelas de Náutica que se fundaron a partir de la segunda mitad del siglo XVIII, para formar pilotos particulares, a excepción de la establecida en Bilbao en 1740, ya que tenía sus propias ordenanzas que le permitía formar, examinar y emitir títulos de piloto y capitán, y el Real Colegio Seminario de San Telmo de Sevilla actuaban como academias preparatorias, destinadas a que los alumnos pudiesen superar el examen de piloto en cualquiera de las Escuelas Departamentales de Navegación de la Armada. Este sistema, no dio el resultado esperado, ya que una serie de naufragios ocurridos en buques mercantes achacados a la mala preparación de los pilotos condujo a la promulgación de la Real Orden de 12 de julio de 1783, sobre exámenes de pilotos, facultando a los directores de Departamento y maestros de Escuelas de Náutica bajo protección real para examinar pilotos.

A partir de ese momento, las Escuelas de Náutica con Real protección quedaron facultadas para examinar y emitir la patente correspondiente, "La sobirana resolució de 12 de juliol de 1783 va permetre que en l'Escola Nàutica d'Arenys de Mar es fessin exàmens de pilot i s'expedissim les corresponents patents, [...]"33.

Esta medida, lo único que cambiaba era la facultad de examinar y emitir títulos de piloto, donde antes sólo podían hacerlo las Escuelas Departamentales de Navegación de la Armada, ahora se ampliaba a las Escuelas de Náutica con Real protección. ¿Esa era la solución a los naufrágios? ¿mantener el programa de estudios y permitir realizar exámenes de pilotos a las Escuelas de Náutica con Real protección?

Por la promulgación del Real Decreto de 8 de julio de 1787, la dirección de los Colegios de San Telmo y las demás Escuelas de Pilotaje de España pasaron a depender de la secretaría de Marina, bajo el mando del capitán general del respectivo Departamento, mientras que la parte técnica quedó sometida al comandante en jefe del Cuerpo de Pilotos de la Armada.

La denominación de los títulos continuaría siendo las establecidas en las OGA, 1748 pilotines, segundo piloto y primer piloto.

Por su extensión, y mejora de su exposición, desarrollamos en el subepígrafe siguiente las clases de piloto reguladas.

\subsection{Clases de pilotos}

En los inicios, los pilotos se clasificaron en función de las carreras para las que estaban examinados. A través de Veitia Linaje nos acercamos a las distintas carreras existentes y sus denominaciones y trayectos: Tierra Firme, que comprendía:

\footnotetext{
33 PONS I GURI, Josep María. Estudi dels Pilots: Assaig monogràfic sobre la Reial Escola de Nàutica d'Arenys de Mar. Barcelona: Curial Edicions Catalanes, 1993, p. 21; Real Orden de 12 de julio de 1783, sobre exámenes de Pilotos, facultando a los Directores de Departamento y Maestros de Escuelas de Náutica bajo protección real para examinar Pilotos, pp. 640-641.
} 
el Cabo de la Vela, Santa Marta, Cartagena, Nombre de Dios y La Habana; Nueva España, que comprendía: la ruta de Santo Domingo y La Habana; y las Islas de Barlovento: constituidas por las islas septentrionales de las Pequeñas Antillas, entre las que están Granada, Martinica, Santa Lucía, Barbados, Guadalupe, Dominica, Trinidad y Tobago ${ }^{34}$. Para cada una de las carreras el aspirante a piloto tenía que ser examinado. Pero aparte de estas derrotas había tantas como puertos de destino, "y así hay pilotos de Honduras, de Margarita, de Puerto Rico [...]", de los que ha inventariado 420 exámenes para pilotos, en los que se detalla para la carrera o carreras que se les habilitaba desde 1568, fecha de la que datan lo que califica de los primeros expedientes académicos de pilotos de la Carrera de Indias hasta $1600^{35}$.

Además de la clasificación a la que nos referimos en este apartado, existía la que se hizo en función de la habilitación que expedía la administración a los pilotos, conviene conocer los tres géneros de pilotos que distingue Escalante de Mendoza en función de los trayectos que realizaban: pilotos de río, son los que traen las naves desde el pasaje de Sevilla hasta aquí donde estamos; pilotos de barra son aquellos que nos llevan desde aquí hasta sacarnos de la barra de Sanlúcar y pilotos de mar, los que van navegando por esos golfos y mares largos en demanda de tierras muy lejanas y remotas ${ }^{36}$.

A las clases de pilotos descritas hay que añadir, asimismo, la que surgió debido a la escasez de pilotos examinados, que posibilitó a profesionales sin los requisitos exigidos para obtener la certificación correspondiente, poder pilotar las naves de la Carrera de Indias. Siguiendo a Pulido Rubio los distinguimos en: pilotos no examinados, aquellos que sin realizar ningún tipo de examen les fue suficiente demostrar que eran prácticos en la navegación; pilotos aprobados, los que realizaron el examen, pero sin seguir las Ordenanzas y pilotos acompañados, entre los que distingue dos tipos: los que estando examinados realizaban el viaje con otro más antiguo y los que sufrían un examen superficial para realizar un viaje determinado ${ }^{37}$.

Las OGA de 1748 establecieron tres clases de pilotos: "Para fervicio de la Armada, havra tres clafes de Pilotos, primeros, fegundos, y Ayudantes, o Pilotines [...]"38. En el artículo siguiente establece la consideración que tendrán dentro del organigrama de la Armada: oficiales de mar. Sin embargo, no establece más diferencia entre primeros y segundos pilotos que la ubicación de su puesto de trabajo, babor o estribor en función de la clase a la que pertenecen, esta será la única distinción que encontraremos en las OGA, 1748 entre los segundos y primeros pilotos 39 .

Por otra parte, las OGA, 1748 fueron mucho más precisas a la hora de delimitar las obligaciones de los pilotos embarcados, atribuyéndoles las siguientes

\footnotetext{
34 VEITIA LINAJE, José. Norte de la Casa de Contratación... Op. cit., p. 154.

${ }^{35}$ NAVARRO GARCÍA, Luis. Pilotos, maestres y señores de naos... Op. cit., pp. 258-275.

${ }^{36}$ ESCALANTE DE MENDOZA, Juan. Itinerario de navegación. Madrid: Museo Naval (1985), 1575, p. 56.

${ }^{37}$ PULIDO RUBIO, José. El Piloto Mayor... Op. cit., pp. 190-192.

38 OGA, 1748, p. 161.

39 OGA, 1748, p. 176.
} 
funciones ${ }^{40}$ :

- Vigilar la conservación de los principales elementos de gobierno: timón y bitácora.

- Cuidar de los utensilios que le correspondían y comprobar que eran conformes con los que el reglamento señalaba.

- Presentar las cartas, compases e instrumentos de tomar alturas, al piloto mayor y al comandante del buque para que comprobasen si estabán correctamente graduados.

- Mantener el rumbo al que tenían que gobernar.

- Prestar atención a las variaciones de las condiciones de mar y viento para asesorar al comandante de la guardia sobre las acciones a tomar.

- Controlar la velocidad y el abatimiento del buque para el cálculo de la situación de estima.

- Calcular la situación del buque -latitud y longitud- corregida por observación del Sol.

- Detallar la latitud, longitud y distancia navegada en la singladura.

- Llevar diario de navegación especificando todos los acaecimientos por singladuras, condiciones de mar y viento, rumbos, etc.

- Reconocer los puntos de tierra según la distancia a la que se encuentre o el ángulo con que las observe, dibujando su contorno.

- Intentar levantar el plano lo más exacto posible, si no es así, anotar en el diario de navegación su sonda y características más importantes (referido a los puertos conocidos).

- Controlar y anotar las variaciones de las agujas, así como los demás acaecimientos que ocurran a bordo.

- Instruir en la náutica a pilotines, alumnos del Colegio de San Telmo, así como a los alumnos de otras Escuelas Particulares (obligación establecida para los primeros pilotos).

- Instruir en la náutica a los guardiamarinas (común a primero y segundos pilotos).

A pesar de existir diferentes clases de pilotos, los cometidos a bordo entre los primeros pilotos y los segundos, poco se diferenciaban entre sí, como hemos podido ver en la referenciada OGA, 1748. En las Ordenanzas Generales de la Armada de 1793 (en adelante OGA, 1793) se siguió con la enumeración de las obligaciones de los pilotos en la misma línea que en las de 1748, con la particularidad que los pilotos primeros y segundos pasaron a ser considerados oficiales mayores ${ }^{41}$. Pero seguía sin establecer diferentes facultades según fuesen primeros pilotos o segundos.

La Real Orden de 12 de julio de 1783, en lo que se refiere a la clasificación de los pilotos fue continuista con la establecida en las OGA, 1748 manteniendo las tres clases: pilotines, segundos pilotos y primeros pilotos, como mostramos en la tabla 6 , en donde establece una doble novedad, por una parte prohíbe terminantemente

40 OGA, 1748, pp. 174-184.

41 Véase: Reglamento general de quanto abraza el total armamento de los navios, fragatas y corbetas de la Real Armada, desde la manga de 29 codos hasta la de 14. Santiago: Ignacio Aguayo y Aldemunde, 1792. En el cual hace relación de los utensilios de la Armada y profesional a su cargo, referencia al piloto en general, sin hacer distinción de clases. 
que el pilotín pueda despachar el buque para cualquier itinerario y por la otra, la posibilidad de emitir el título restringido para Europa, en aquellos casos que no se hayan realizados los preceptivos viajes a América, conservando la denominación de piloto de la Carrera de Indias para aquellos que cumplimenten los viajes a América establecidos para cada clase ${ }^{42}$.

\begin{tabular}{|c|c|c|}
\hline \multicolumn{3}{|c|}{$\begin{array}{l}\text { Clases de pilotos y requisitos de capacidad, conforme La Real Orden de } 12 \text { de } \\
\text { julio de } 1783\end{array}$} \\
\hline Grado & Requisitos & Pajes \\
\hline Pilotín 43 & $\begin{array}{l}\text { Hombre de buena conducta y loables costumbres. } \\
\text { Realizar dos viajes redondos a América/o un viaje solo y algunas } \\
\text { travesías/o un viaje redondo y algunas campañas a Europa en } \\
\text { buques del Rey. Los viajes debían ser acreditados mediante } \\
\text { certificación emitida por el dueño del buque intervenida por el } \\
\text { Juez de matrícula. En el caso de no haber realizado los } \\
\text { preceptivos viajes a América, sólo estaban facultados para } \\
\text { navegar por Europa. }\end{array}$ & 2 \\
\hline $\begin{array}{l}\text { Segundo } \\
\text { Piloto }\end{array}$ & $\begin{array}{l}\text { Tres viajes redondos a América. Los viajes debían ser } \\
\text { acreditados mediante certificación emitida por el dueño del } \\
\text { buque intervenida por el juez de matrícula. En el caso de no } \\
\text { haber realizado los preceptivos viajes a América, sólo estaban } \\
\text { facultados para navegar en Europa. }\end{array}$ & 4 \\
\hline $\begin{array}{l}\text { Primer } \\
\text { Piloto }\end{array}$ & $\begin{array}{l}\text { Tener veinte y cinco años y cinco viajes a América. Los viajes } \\
\text { debían ser acreditados mediante certificación emitida por el } \\
\text { dueño del buque intervenida por el Juez de matrícula. En el caso } \\
\text { de no haber realizado los preceptivos viajes a América, sólo } \\
\text { estaban facultados para navegar en Europa. }\end{array}$ & 5 \\
\hline
\end{tabular}

Tabla 6: Clases de pilotos y requisitos de capacidad, conforme La Real Orden de 12 de julio de 1783. Fuente: Elaboración propia a partir de La Real Orden de 12 de julio de 1783.

En 1786 se promulgaron las Ordenanzas para el Real Colegio de San Telmo de Sevilla, con el objetivo de contar con más profesionales instruidos en la ciencia náutica, y más escuelas para su formación. Las mencionadas Ordenanzas fijaron un plan de estudios académicos, las prácticas profesionales, la clasificación de los pilotos y los requisitos que tenían que cumplimentar para obtener las titulaciones profesionales. Al finalizar los estudios académicos, que duraban cuatro años, los aprobados embarcaban como agregados al rancho de pilotos, en los barcos de la Real Armada y en los de la marina mercante que hacían la ruta a Indias. Las titulaciones profesionales obtenidas después de cursar los estudios y cumplimentar los requisitos establecidos en las mencionadas Ordenanzas, que se detallan en la tabla 7, se clasificaron en dos clases: pilotines y pilotos.

\footnotetext{
42 Real Orden de 12 de julio de 1783... Op. cit., p. 642.

43 La duración de los estudios para alcanzar el grado de pilotín según PONS I GURI, Josep María. Estudi dels Pilots... Op. cit., dependía del nivel de estudios del alumno, pero normalmente era de dos años.
} 


\begin{tabular}{|l|l|l|}
\hline \multicolumn{3}{|c|}{ Clases de pilotos y requisitos de capacidad, conforme Ordenanzas para el } \\
Colegio de San Telmo de Sevilla de 1786
\end{tabular}

Tabla 7: Clases de pilotos y requisitos de capacidad, conforme Ordenanzas para el Colegio de San Telmo de Sevilla de 1786. Fuente: Elaboración propia a partir Ordenanzas para el Colegio de San Telmo de Sevilla de 1786.

Con la puesta en marcha del plan de estudios Winthuysen en $1790^{44}$, los pilotos se clasificaron en: pilotines, segundos pilotos y primeros pilotos, manteniendo la denominación establecida en las OGA, 1748. Esta clasificación se mantuvo hasta el 1890, que se modificó por Real Orden de 20 de mayo, en la que quedarían establecidos los títulos de Capitán de la Marina Mercante y Piloto de la Marina Mercante ${ }^{45}$.

La designación de piloto no sólo se utilizó para determinar la profesión que se ejercía, sino también para la designación de cargos. Tenemos constancia de la existencia de diferentes cargos en los que se utilizó la denominación de piloto como los de piloto mayor de la Casa de Contratación de Sevilla, formador y examinador de pilotos de la Carrera de Indias y censor de las cartas e instrumentos de navegación, el piloto mayor de la Armada Real de la guardia de la Carrera de Indias, el piloto mayor de las flotas de Nueva España. Entre los que José Veitia Linaje atribuye la relevancia del piloto mayor de la Casa de Contratación de Sevilla "por qué es preeminente en grado, y lo debe fer en fabiduría, fiendo el puefto á que le vendrian bien todas aquellas propiedades, virtudes, y ciecias, que el Capitan Francisco de Ruef (quien dignamente ocupa ahora este puefto) [...]"46. También la Armada utilizó esta designación en las OGA, 1748 al crear el cargo de piloto mayor de la Armada.

\footnotetext{
44 MNM. Ms. 895, doc. 1, fol. 1-7: "Instrucción General para la disciplina, estudios y exámenes que deben seguirse en las Escuelas Reales y Particulares de Náutica del Reino, Formada por D. Fco. Winthuysen y aprobadas en 26 de febrero de 1790".

45 Por Real Decreto de 20 de mayo de 1890 (Gaceta de Madrid de 27 de mayo de 1890), se redujeron las clases de pilotos a dos: "Capitán de la Marina Mercante" y "Piloto de la Marina Mercante".

46 VEITIA LINAJE, José. Norte de la Casa de Contratación... Op. cit., p. 139.
} 


\section{Consideración social del piloto}

En la Edad Moderna, trabajar en la mar a bordo de un buque mercante significaba adentrarse en un mundo laboral totalmente diferenciado de los distintos trabajos que se realizaban en tierra. El medio en donde se desempeñaba, la mar, no siempre era favorable a los tripulantes, y condicionaba su duro trabajo a bordo. A lo que había que añadir tripulaciones excesivas relacionadas con las escasas dimensiones de los buques dedicados a la Carrera de Indias, que, según su tonelaje, oscilaban entre 30 y 64 hombres, de acuerdo con la tabla 5 , sin olvidar el pasaje con destino a las Indias. En ese espacio reducido convivían hombres y mujeres, animales domésticos y carga, en unas condiciones de hacinamiento y escasa, por no decir nula, higiene personal, lo que, unido a las cambiantes condiciones meteorológicas en la mar, se podía convertir en una situación insufrible. Como así lo narró Eugenio Salazar en la carta que le escribe a su amigo el licenciado Miranda de Ron, en la que describe un navío y la vida que hacen los oficiales y marineros ${ }^{47}$. También Fray Tomás de la Torre al describir el navío reflejó la dureza de la vida a bordo "el navío es una cárcel muy estrecha y muy fuerte de donde nadie puede huir, aunque no lleve grillos ni cadenas, y tan cruel que no hace diferencia entre los presos; igualmente los trata y estrecha a todos"48. Estos dos autores, junto con Antonio de Guevara, que en 1539 narró la difícil vida en una galera, son los tres autores de la época que relataron la dureza del día a día a bordo. En los largos y duros viajes, tripulantes y pasajeros compartían el lugar de residencia y trabajo, su encierro, la rutina diaria, aislados de la sociedad, en el buque como institución total ${ }^{49}$.

Cesáreo Fernández Duro enumera todas las carencias, inseguridades, sufrimientos, venturas y desventuras que tenía que soportar el pasajero que se embarcaba. Describe las relaciones entre ellos y tripulantes, la convivencia y la imperativa con roedores, blatodeos, así como diferentes especies de parásitos por compañeros de viaje. A lo que añade las incomodidades que los acompañarán, la falta de intimidad, el hacinamiento, los malos olores, que según las crónicas eran insoportables. Sin olvidar lo que podía suponer las calmas o temporales, en unidades de escasas dimensiones y sobrecargadas, que agravaba los efectos de las condiciones meteorológicas y aumentaba las dificultades de realizar las labores marineras para correr el temporal ${ }^{50}$. Estas penurias que tenían que soportar los tripulantes, por la dureza del trabajo en la mar, y las condiciones de alojamiento y alimentación que padecían a bordo, repercutían negativamente en su estado físico,

\footnotetext{
47 SALAZAR, Eugenio. Cartas de Eugenio de Salazar, vecino y natural de Madrid, escritas à muy particulares amigos suyos, publicadas por la sociedad de bibliófilos españoles. Madrid: Imprenta y Esterotipia de M. Rivadeneyra, 1573 (edición 1866).

48 TORRE, Tomás de la (Fray). Diario de viaje de Salamanca a Ciudad Real de Chiapa, 1544-1545. Caleruega (Burgos): OPE, 1985, p. 63.

49 Véase: MIRA CABALLOS, Esteban. La vida y muerte a bordo de un navío del siglo XVI: Algunos aportes. Revista de la Historia Naval. 2010, n. 108, pp. 39-57; En cuanto el buque como centro de trabajo y vida en el cual los tripulantes y en su caso el pasaje, sólo tienen ocasión de relacionarse entre sí, alejados de elementos externos. RODRÍGUEZ-MARTOS I DAHUER, Ricardo. El buque mercante un análisis sociológico. Barcelona: UPC, 1996.

50 Véase: FERNÁNDEZ DURO, Cesáreo. Disquisiciones Náuticas. La Mar descrita por los mareados. Vol. 4. Madrid: Impresores de Cámara de S.M, 1877.
} 
tanto es así que presentaban una imagen de temprano envejecimiento ${ }^{51}$.

La organización del trabajo, con el piloto y maestre en la dirección técnica y comercial de la nave, estaba distribuido entre marineros, grumetes y pajes, que realizaban las labores habituales como mantener las cubiertas limpias, reparar e izar las velas cuando fuera preciso, atar cabos, reparación de estachas y velas, achicar el agua, revisar los aparejos, mantenimiento y reparaciones. La fuerza de trabajo utilizado en la mar estaba compuesta de forma diferente a la constituida en la producción industrial, que básicamente estaba integrada por la mano de obra aportada por el grupo familiar, es decir, por el maestro artesano y la ayuda proporcionada por su mujer y sus hijos más los parientes, quedando sujetos a la autoridad del maestro ${ }^{52}$.

Como contraposición, en la mar, la autoridad provenía del piloto y del maestre, la base de la fuerza de trabajo no se originaba en el grupo familiar, sino que esta era muy heterogénea, y de diversa calidad humana ${ }^{53}$.

Completaban las tripulaciones aquellos que, atraídos por la idea de un futuro mejor, deseaban emigrar a América, al no disponer de los fondos necesarios para pagarse el pasaje, ni reunir los estrictos requisitos que imponía la Corona española, se enrolaban como marineros. Lo que no era tarea difícil, a pesar de no tener ninguna experiencia marinera, debido a las dificultades que existían para completar las tripulaciones de las flotas de Indias. Constituyéndose ese procedimiento en una forma peculiar de emigrar a América, ya que a la llegada a tierra desertaban, a pesar de que los castigos establecidos para los desertores eran duros. Por lo que no eran otra cosa que "emigrantes disfrazados de hombres de mar" 54.

En la Edad Moderna, el estamento que soportaba la fuerza del trabajo correspondía al pueblo llano (tercer estamento), ya que la nobleza y el clero eran improductivos. Para la nobleza el trabajo manual constituía un agravio para el honor. La clasificación de algunos oficios como viles, los hacía incompatibles con la hidalguía y los cargos públicos. Esta situación perduró hasta la promulgación de la Real Cédula de 18 de marzo de 1783 de Carlos III55.

La gente de mar, dentro del tercer estamento, generalmente pertenecía a la clase más desfavorecida. Por el medio en el que se desarrollaba, la profesión de marinero resultaba peligrosa y, por ello, a ella solo se dedicaba la gente pobre, que no solía tener otra opción para ganarse la vida. Muchos de ellos eran reclutados

\footnotetext{
51 Véase: MARTÍN GARCÍA, Alfredo. Entre el mar y la muerte. Procedencias, condiciones de vida y mortalidad de los navegantes en el Real Servicio (1776-1804). Espacio, Tiempo y Forma, Serie IV, $H^{a}$. Moderna. 1999, n. 12, pp. 415-441.

52 Véase: MARCOS MARTÍN, Alberto. España en los siglos XVI, XVII y y XVIII. Barcelona: Crítica, 2000.

${ }^{53}$ FERNÁNDEZ ALMAGRO, Melchor. Política naval de la Edad Moderna y Contemporánea. Madrid: Instituto de estudios políticos, 1946, p. 30.

54 PÉREZ-MALLAínA BUENO, Pablo Emilio. Los Hombres del Océano. Vida cotidiana de los tripulantes de las flotas de Indias. Siglo XVI. Sevilla: Servicio de Publicaciones de la Diputación de Sevilla, 1992, p. 36.

55 GARCíA GARROSA, María Jesús. La Real Cédula de 1783 y el teatro de la ilustración. Bulletin Hispanique. 1993, vol. 95, n. 2, pp. 673-692.
} 
entre familias numerosas, que los padres no tenían posibilidad de alimentar, o directamente recogidos de la calle, como es el caso de la procedencia y origen del piloto Francisco Manuel ${ }^{56}$.

Como se ha mencionado anteriormente, la posición social y el escaso poder adquisitivo de la gente de mar, sirvió como pretexto para reducir en 1555 el periodo de oír la lectura de la Cátedra de Cosmografía, argumentándose la pobreza de los aspirantes a pilotos que no tenían otro medio de sustento que su trabajo ${ }^{57}$.

La pertenencia de la gente de mar al tercer estamento, en principio, supuso una brecha infranqueable para que los hidalgos se dedicasen a las profesiones del mar, como quedó manifestado en la cédula emitida en Madrid el 27 de enero de 1582, por la que se concedía a los vizcaínos el permiso para ir de maestres de sus navíos, con la doble condición de llevar dos pilotos examinados y que renunciasen a su hidalguía. La exigencia de la renuncia a la hidalguía permaneció hasta la promulgación de la cédula dada en Madrid a 19 de marzo de 1609, en la que en el capítulo 14 se alentaba a los hidalgos a servir en la mar, como cualidad de más honra y estimación: "Que el servir en la mar no perjudique á los hijofdalgo, ni a fus fucefsores, antes les fea qualidad de mas honra, y eftimacion" 58 .

La categoría social fue la respuesta a las siguientes preguntas: “¿Por qué era tan raro que los marinos españoles ascendiesen hasta el grado de almirante 0 capitán general? ¿Y qué impedía a los nobles empezar su carrera en la marina sirviendo como grumetes?" La solución que sugería el capitán general de la flota Atlántica Martín Padilla consistía en el reconocimiento público de los méritos de los marinos, mediante la puesta en marcha de una serie de medidas en los distritos marítimos, encaminadas a ensalzarlos. A la par que Diego Brochero almirante general de la Armada del Mar Océano y segundo de Martín Padilla consideraba que el reconocimiento social de los marinos ingleses y holandeses había repercutido en sus victorias navales. Mientras en España, la de marino "era una ocupación tan despreciada que a nadie se estima menos en la nación española que a los marinos" 59 .

El criterio seguido en toda Europa para elegir el mando de las fuerzas armadas era el mismo, pertenencia a la nobleza. El fracaso de la Armada Invencible (1588) planteó la posibilidad de que los capitanes de flotas fuesen marinos, pero Brochero, a pesar de apoyar a los marinos expertos, se oponía, al considerar que no tenían las cualidades necesarias para ostentar el mando de un galeón, ya que no eran nobles y no podían ganarse el respeto de un capitán de infantería, "El punto de vista

56 PÉREZ-MALLAÍNA BUENO, Pablo Emilio. La Creación de la Universidad de Mareantes. Cuadernos monográficos del Instituto de Historia y Cultura Naval. 2001, n. 43-62, p. 49.

57 Véase: GARCIA FRANCO, Salvador. Historia del arte y ciencia de navegar. Desenvolvimiento histórico de los cuatro términos de la navegación. Vol. 2. Madrid: Instituto histórico de Marina, 1947, p. 177; PULIDO RUBIO, José. El Piloto Mayor... Op. cit., pp. 80-82; NAVARRO GARCÍA, Luis. Pilotos, maestres y señores de naos... Op. cit., p. 277. CHAUNU, Pierre. La Expansión Europea (siglos XII al XV). Barcelona: Labor, 1977, p. 220; PÉREZ-MALLAínA BUENO, Pablo Emilio. Los Hombres del Océano ... Op. cit., p. 36.

58 VEITIA LINAJE, José. Norte de la Casa de Contratación... Op. cit., p. 123.

59 GOODMAN, David. El poderío naval español: Historia de la armada española en el siglo XVII. Barcelona: Península, 2001, p. 338. 
de Brochero sobre esto demuestra que pese a todos los años que había pasado en la mar su mentalidad seguía siendo la de un soldado"60.

A pesar de la brecha económica existente entre señores de naos, maestres, pilotos y marineros, la desconsideración social de la gente de mar era generalizada. La falta de consideración social del piloto venía dada por el carácter práctico del ejercicio de la profesión, unido a que era requisito indispensable para poderse examinar de piloto haber navegado de marinero durante seis años, "¿quién sino un marinero acostumbrado a ganar soldada y a habitar bajo el puente como cualquier otro se acercaría a oír las lecciones de cosmografía?"61.

A los señores de naos, tampoco se les tenía en mayor consideración, los oficiales de la Casa de Contratación los recibían sentados, haciéndoles permanecer a ellos de pie, por lo que se sentían humillados, ya que a los representantes de los comerciantes les permitían tomar asiento. Después de elevar protesta, se les permitió tomar asiento. La poca consideración social hacia los señores de naos, y en general hacia la gente de mar, quedó reflejada cuando, por falta de personal para ocupar las plazas de maestres de ración, en 1584, fueron convocados cuatro importantes señores de naos que tenían en común ser maestres o pilotos de la carrera de Indias, entre los cuales estaban: Andrés de Paz, diputado de la Universidad de los capitanes, y dueños de naos de la navegación de las Indias, que había ejercido de capitán, y Cristóbal Monte Bernardo que había servido de almirante en flotas y armadas y de general. Ante lo que consideraron una afrenta, apelaron la orden y acudieron al Rey, pero hay que recordar que fueron convocados por su condición de maestres y pilotos de la Carrera de Indias. El origen actuaba como un estigma que los acompañaba durante toda su vida, por mucho que tratasen de olvidarlo cuando alcanzaban una posición económica acomodada, como es el caso de estos cuatro señores de naos, que en el momento que los trataron como simples maestres o pilotos de la Carrera de Indias remarcaron cuál era su condición ${ }^{62}$.

La categoría social fue decisiva para poder acceder a los altos cargos de las flotas ya que la corona siguió una política consistente en nombrar a los altos cargos entre miembros de la nobleza, que generalmente no poseían conocimientos náuticos, lo que provocó quejas por parte de la Universidad de Mareantes que, como heredera de los cómitres, solicitó en 1608, se les confirmasen los antiguos privilegios concedidos a los maestres y pilotos examinados. A estos privilegios no cumplidos, añadían que no se tenía en cuenta a sus miembros más destacados, para los nombramientos de generales y almirantes de flotas y galeones, a lo que solicitaban se les confirmasen los privilegios concedidos antaño por los Reyes a los cómitres. La respuesta de la Corona fue ambigua y la Universidad de Mareantes lo interpretó de una forma favorable a sus intereses, pero la realidad, es que los nombramientos se siguieron realizando bajo el mismo criterio y sin tener en cuenta la experiencia náutica para el desempeño de los altos cargos, a los cuales teóricamente se llegaba por las vías que se señalan en la fig. 1.

\footnotetext{
60 GOODMAN, David. El poderío naval español... Op. cit., p. 338.

61 NAVARRO GARCÍA, Luis. Pilotos, maestres y señores de naos... Op. cit., p. 277.

62 NAVARRO GARCÍA, Luis. Pilotos, maestres y señores de naos... Op. cit., pp. 277- 279.
} 

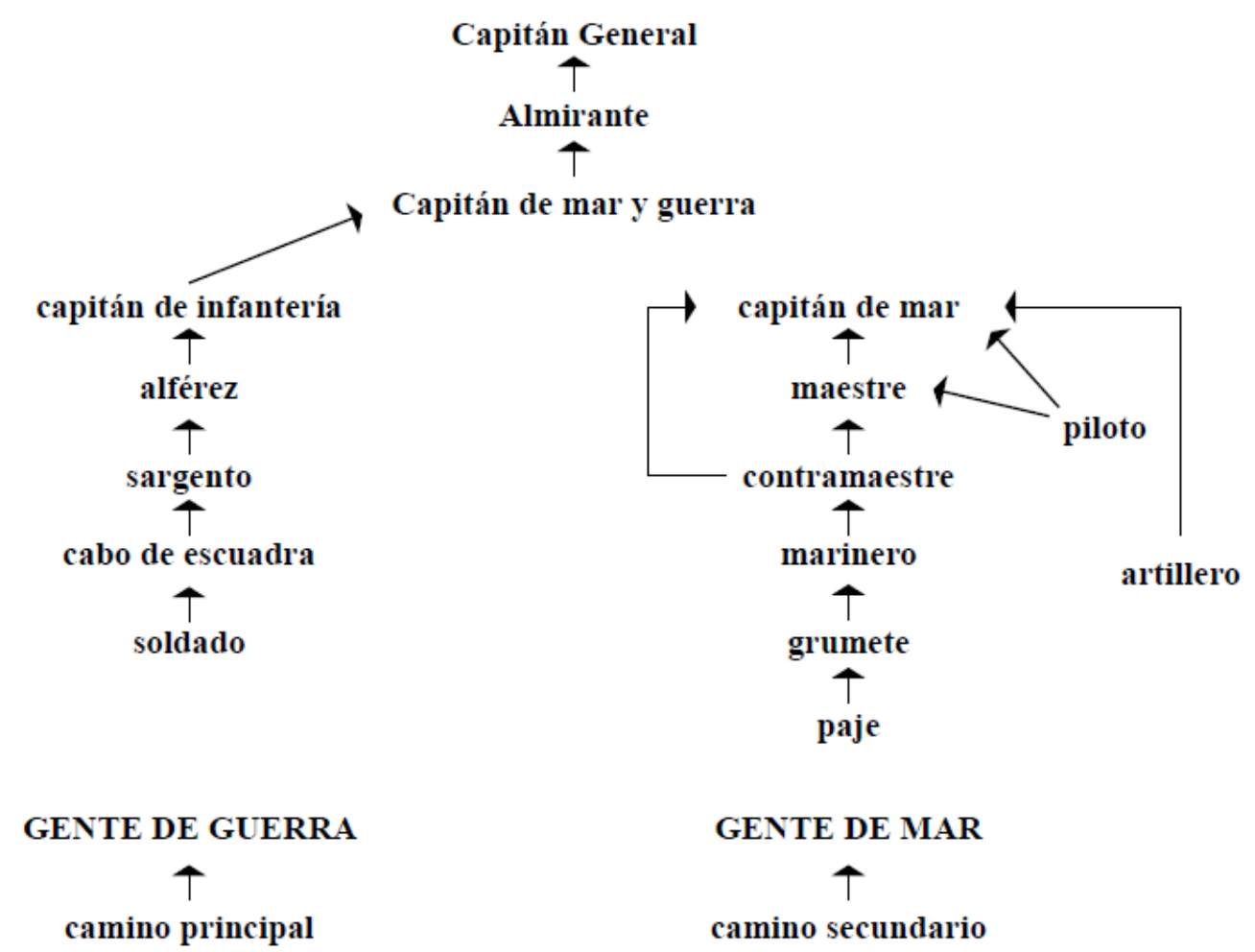

Fig. 1: Vías para alcanzar los grados superiores de la Armada. Fuente: Goodman ${ }^{63}$.

La Universidad de Mareantes también solicitó para pilotos y maestres el privilegio de hidalguía, tanto para ellos mismos como para sus descendientes (véase fig. 2.). En el parecer emitido por don Francisco de Varte, en razón al memorial presentado por los diputados de la Universidad de Mareantes al Rey, refleja su consideración a que no les sea concedido el privilegio de hidalguía.

${ }^{63}$ GOODMAN, David. El poderío naval español... Op. cit., p. 326. 


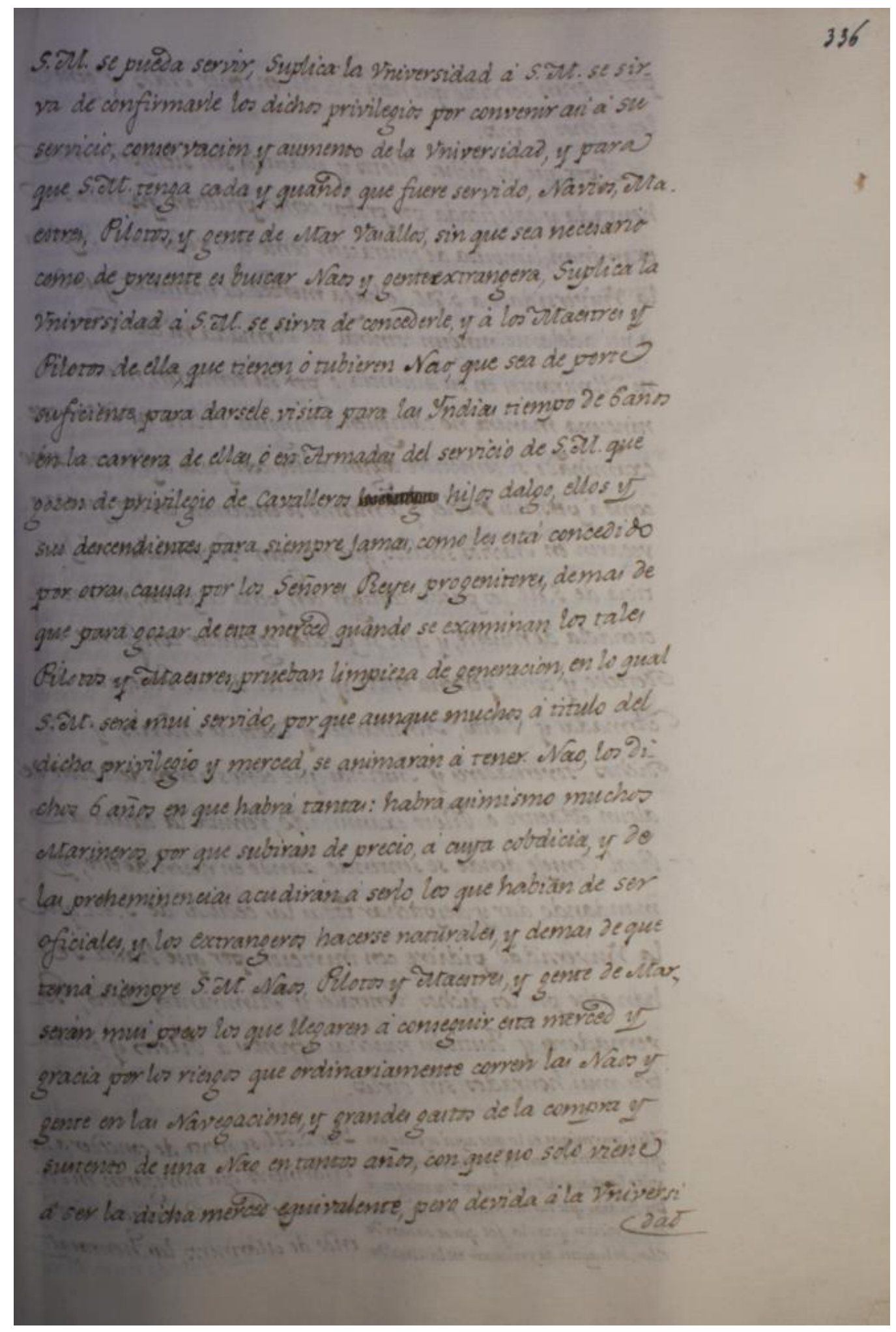

Fig. 2: Solicitud de la Universidad de Mareantes al Rey para la concesión de privilegios de caballeros hidalgos para los maestres y pilotos. Fuente: M.N.M., Ms. 32. Colección Martín Fernández de Navarrete, fol.336.

Como respuesta a las presiones ejercidas desde la Universidad de Mareantes, la Corona siguió intentando subir la categoría social de los marinos, pero los privilegios y exenciones concedidos por la Corona, a pilotos y maestres fueron de escaso 
calado por una parte los igualaban a los artilleros y por otra les pedía a los generales de las flotas de forma genérica que les diesen buen tratamiento a los pilotos ${ }^{64}$.

Todas estas disposiciones, que en poco mejoraban la consideración social de los pilotos, ni las de trabajo a bordo, trataban de fomentar las "vocaciones marineras", que en aquellos tiempos eran tan escasas. El medio en que se desarrollaba la profesión, las condiciones de las naves, y el tener que iniciarse como paje, hacían que la profesión de piloto careciese de atractivo para los hijos de la nobleza y de la burguesía. En ese contexto, la Carrera de Indias a principio del siglo XVII empleaba unas 9.000 personas distribuidas en todos los cargos, que no siempre era posible cubrir con personal español, siendo necesario tener que recurrir al extranjero ${ }^{65}$.

Frente a la situación creada por la escasez de gente de mar, y según Jiménez Jiménez ${ }^{66}$ por la competencia náutica de otras naciones, el Duque de Medinaceli en 1607 proyectó la creación de un colegio de marinos, este proyecto no prosperó quedando estancado, volviéndose a retomar en 1627, para finalmente hacerse realidad en 1681, mediante cédula de 17 de junio por la cual se creó el Colegio de San Telmo de Sevilla67 "[...] para recoger, criar, y heducar muchachos huérfanos, y desamparados, enseñándoles la marinería, Pilotage, y Artilleria [...]"68.

En la cédula fundacional del Colegio Seminario de San Telmo en 1681, entre los requisitos que se exigían a los aspirantes estaban: no ser extranjero, ser pobre, preferencia de huérfanos sobre aquellos que tuviesen a sus padres vivos y al menos de ocho años de edad ${ }^{69}$. Estos requisitos se complementaron el 27 de julio de 1721 , con la prohibición del ingreso a los hijos de padres que ejerciesen alguno de los oficios clasificados como viles. Esta nueva condición se estableció como consecuencia de la reunión que mantuvo la administración del Colegio de San Telmo, debido a que algunos antiguos alumnos del Colegio de San Telmo de Sevilla empezaban a sobresalir como capitanes de mar y guerra, pilotos, condestables de artillería, religiosos, etc., consideradas profesiones nobles que tenían asociados privilegios como no pagar tributos, ni derechos, ni tener que alojar huéspedes o soldados en sus casas. Con lo cual los hijos de notorias familias con escasez de medios económicos, no se sentirían humillados ${ }^{70}$.

\footnotetext{
${ }^{64}$ Anónimo. Recopilación... Op. cit., pp. 306-307.

65 PÉREZ-MALLAíNA BUENO, Pablo Emilio. Los Hombres del Océano ... Op. cit., p. 60.

66 JIMÉNEZ JIMÉNEZ, Elisa María. El Real Colegio Seminario de San Telmo de Sevilla (1681-1808).

Sevilla: Universidad de Sevilla, 2002

${ }^{67}$ Aunque este centro se tratará de forma más amplia en el capítulo tercero, es oportuno incluir aquí aquellos aspectos que hacen referencia a la condición social de los que se dedicaron a los oficios del mar.

68 Véanse: JIMÉNEZ JIMÉNEZ, Elisa María. El Real Colegio... Op. cit.; BARRAS DE ARAGÓN, Francisco de las. Circunstancias que motivaron la fundación del Colegio de San Telmo de Sevilla. Madrid: Asociación Nacional de Historiadores de la Ciencia Española, 1935, p. 37.

69 BARRAS DE ARAGÓN, Francisco de las. Circunstancias que motivaron... Op. cit., p.39.

70 Véanse: REBOLLO ESPINOSA, María José. Desprestigio social y oficios viles en la España del siglo XVIII. Ascendencia socio profesional del alumnado del Real Colegio Seminario de San Telmo de Sevilla. Cuestiones pedagógicas. 1988, n. 45, pp. 211-227; JIMÉNEZ JIMÉNEZ, Elisa María. El Real Colegio... Op. cit.
} 
A pesar del empeño puesto, la profesión marinera seguía sin atraer a los hijos de notorias familias. En las Ordenanzas de 1786 continuaron los requisitos de orfandad y pobreza, aunque se crearon 50 plazas para porcionistas, estableciendo condiciones diferentes para el acceso al Real Colegio de San Telmo de Sevilla. Mientras los porcionistas pagaban una cuota diaria por su estancia y formación, los de número debían reunir los requisitos de pobreza, orfandad o ser hijos de pilotos y demás gente de mar. Los colegiales porcionistas eran jóvenes pertenecientes a la nobleza y por lo tanto situados al otro extremo de la escala social en la que estaban los de número, con los que compartían profesorado y enseñanza, a excepción de lo que se refería a las prácticas de embarque, que solo eran obligatorias para los de número, para la profesión de pilotaje o de cualquier otro oficio relacionado con la mar $^{71}$. Al final de la formación, emprenderían caminos diferentes, que, en el caso más favorable, para los colegiales de número culminaría en la obtención del título de piloto. En efecto, entre 1791 y 1810 ingresaron 190 colegiales porcionistas de origen noble, presentado las pruebas de nobleza de rigor. Aunque prácticamente recibieron la misma formación que los colegiales de número, ninguno de los porcionistas embarcó ni ejerció profesiones relacionadas con la mar ${ }^{72}$. Compartieron en el mismo centro de formación, y estudios, con proyectos totalmente diferentes. El objetivo final que tenía el Colegio de San Telmo con respecto a los colegiales de número era formar a los colegiales para ejercer profesiones relacionadas con la mar $^{73}$, mientras que para los porcionistas consistía en seguir el criterio ilustrado de instruir a la nobleza.

Coincidieron en un mismo centro de formación, por tanto, los miembros de la parte baja de los dos estamentos extremos. El primero compuesto por la nobleza, en el que se distinguía la alta nobleza formada por duques, condes y marqueses y la baja nobleza, por hidalgos. Por otra parte, los niños pobres y huérfanos pertenecientes a la capa más baja del tercer estamento. El tercer estamento estaba compuesto por el pueblo llano, variando su composición entre las ciudades y los pueblos. En las ciudades existía un amplio sector medio'burguesía', compuesta por los que administraban las ciudades, a los que a su vez estaban subdivididos en dos niveles, el superior compuesto por mercaderes, funcionarios, y profesionales liberales, en el nivel inferior los miembros de los gremios, corporaciones, asociaciones y comerciantes, a los que se pueden añadir los trabajadores no cualificados $^{74}$. Dentro de los oficios ejercidos por los componentes del tercer estamento estaban los que la pragmática de 1447 de Juan II de castilla, refiriéndose a cuáles son los oficios prohibidos a los caballeros armados, declaró bajos y viles, a

71 GARCÍA GARRALÓN, Marta. Taller de mareantes. El Real Colegio Seminario de San Telmo de Sevilla (1681-1847). Vol. 2. Sevilla: Cajasol Obra Social, 2007, pp. 160-167.

72 Como así se desprende de: DELGADO Y ORELLANA, José Antonio. Catálogo de pruebas de nobleza del Real Colegio de San Telmo de Sevilla. Madrid: Hidalguía, 1985; y del examen de los documentos del Real Colegio Seminario de San Telmo de Sevilla y su formación práctica, desde 1682 en que ingresan los primeros colegiales hasta 1841. La información procede de los documentos del Real Colegio Seminario de San Telmo que se custodian en el Archivo Histórico de la Universidad de Sevilla (AHUS) desde 1847, fecha en que se suprime el Colegio (AHUS, Libros 217-281, 284-285 y 308).

73 Ordenanzas para el Real Colegio de San Telmo de Sevilla. Madrid: Imprenta de la Viuda de Ibarra, 1786.

74 RODRÍGUEZ CANCHO, Miguel. Cambios y tensiones sociales en el siglo XVII. En: FLORISTÁN, A. Historia moderna universal. Barcelona: Editorial Planeta, 2016. 
saber: sastre, pellejero, carpintero, pedrero, tundidor herrero, barbero, especiero, recatón y zapatero ${ }^{75}$. En los pueblos, el campesinado estaba formado por los labradores (campesinos con tierras), los jornaleros (campesinos sin tierras) y los mozos de labranza. Dentro de este tercer estamento se encuadraban también los pobres, vagabundos y delincuentes. Una de las condiciones exigidas para acceder como colegial de número al Colegio de San Telmo era ser hijo de familia sin nota particular y pobre ${ }^{76}$.

También el estrato social al que pertenecía el piloto condicionó su incorporación a la Marina de guerra, caracterizada por el trato desigual que recibió el Cuerpo de Pilotos comparado con el Cuerpo General, fundamentado en los siguientes puntos:

- No tuvieron derecho a usar uniforme de la Armada hasta el 16 de enero de 1770.

- $\quad$ No tuvieron tratamiento de Don hasta la Real Orden de 2 de mayo de 1781.

- Fueron incluidos entre los oficiales de mar hasta 1793, que pasaron a ser considerados como oficiales mayores.

- Diferencias en el trato, el servicio y la paga.

- Política lenta de ascensos ${ }^{77}$.

No se puede olvidar la obligación a embarcar como pajes, grumetes y marineros en los periodos entre estudios, previo a la obtención del grado de pilotín o tercer piloto. A modo de ejemplo, en la fig. 3, correspondiente al estado de los alumnos que estudian 'con plaza y ración' en la Escuela de Navegación del Departamento de Cartagena en 1801, se refleja, entre otros datos, el empleo que desempeñaban los aspirantes a pilotos de la Armada entre periodos de estudio.

La corriente que imperaba entonces en la Armada, en la que el ideal del buen oficial de Marina, influenciado por la opinión del Almirante Nelson, era la de un buen práctico en la maniobra de las velas y todo lo que tenía que ver con las maniobras necesarias para poder abordar a otro buque o echar el ancla en el lugar deseado. Por ello a los que sabían determinar la posición del buque por medios astronómicos, se les tachó de sabios. A pesar de ser necesario el piloto a bordo de los buques, en las misiones científicas, o como catedráticos, maestros o profesores en las compañías de guardiamarinas, fue menospreciado y vejado en el contacto con los oficiales, a la vez que se le limitó su carrera profesional ${ }^{78}$.

\footnotetext{
75 Tomo segundo de las leyes de recopilación que contienen los libros sexto, septimo, octavo y nono. Madrid: Herederos de la viuda de Juan García Infanzón, 1745.

76 Ordenanzas para el Real Colegio de San Telmo de Sevilla... Op. cit., p.3.

77 ALÍA PLANA, José Miguel. La enseñanza de la náutica en la Armada Española (1717-1820) [tesis doctoral]. Madrid: Universidad Nacional de Educación a Distancia, 2001, pp. 274-276.

${ }^{78}$ Véase: FERNÁNDEZ DURO, Cesáreo. Disquisiciones Náuticas. Los ojos en el cielo. Vol. 4. Madrid: Impresores de Cámara de S.M., 1879.
} 


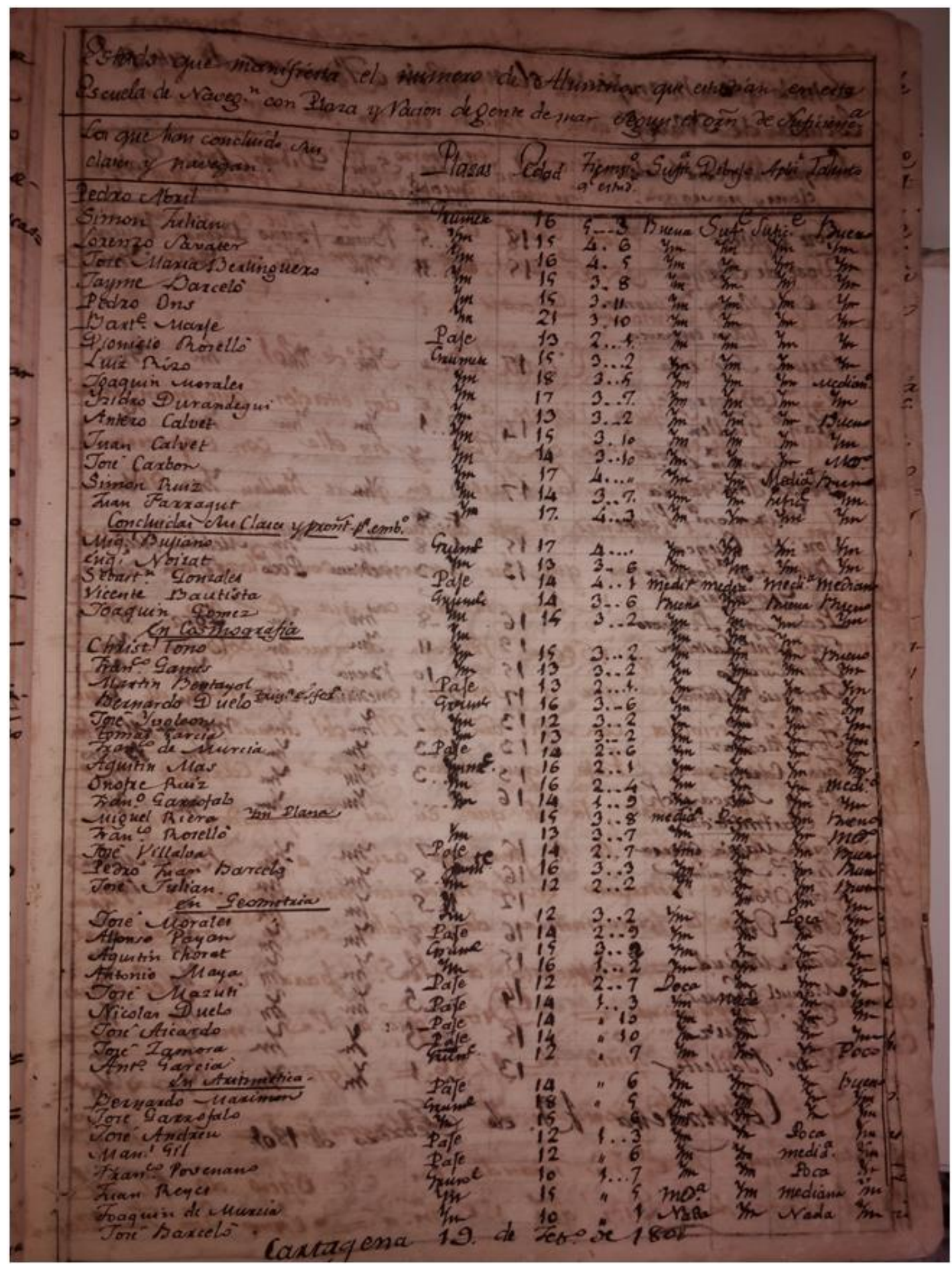

Fig. 3: Estado que manifiesta el número de alumnos que estudian en esta Escuela de Navegación (Cartagena, 1801) con plaza y ración de gente de mar según el orden de suficiencia. Fuente: ANC, Caja 886. Libro ํo 1.

Como dice José Miguel Alia Plana citando a Cesáreo Fernández Duro, una serie de pilotos fueron profesores de la Escuela de Guardiamarinas como Pedro Manuel Cedillo (1676-1761), director de la Escuela de Guardiamarinas de Cádiz, Antonio Gabriel Fernández (1702- ¿ ?), maestro de Matemáticas en Cádiz y a Domingo Martínez en la Academia de Ferrol, al que añadimos a Nicolás Josef Bufiano (¿?-1794), 2ำ maestro de la Escuela de Navegación de Cartagena, a quien 
por Real Orden de 13 de noviembre de 1777, su Majestad concedió el empleo de maestro tercero de la Academia de Guardiamarinas de este Departamento, con un sueldo de 70 escudos al mes. Como segundo maestro de la Escuela de Navegación, su sueldo asignado era de 35 escudos al mes, siendo el del primer maestro 50 escudos $^{79}$. De ello se infiere que la discriminación también alcanzaba a los salarios de los profesores.

En la cadena de mando faltando todos los oficiales de guerra, las OGA, 1793, continuaban situando a los pilotos por debajo de los guardiamarinas ${ }^{80}$.

Su carrera profesional como sostiene Marta García Garralón se limitaba a alcanzar el grado de primer piloto sobre los 35 o 40 años después de haber estado navegando constantemente, desde ser examinado y aprobado en la escuela. José María Blanca Carlier refiere que, en un principio, los primeros y segundos pilotos fueron graduados de alférez de fragata y de oficiales mayores respectivamente. Con el tiempo a los primeros pilotos se les graduó de tenientes de navío o de fragata, según la antigüedad y a los segundos de alféreces de navío o de fragata. Por relevantes servicios a algunos pilotos se les integró en el Cuerpo General con empleos efectivos, causando baja en el Cuerpo de Pilotos. Estas incorporaciones al Cuerpo General no fueron de un modo natural, siguiendo una carrera profesional lógica, sino que se producían motivadas por hechos que podríamos calificar de excepcionales, quedando suprimido el pase de un cuerpo a otro durante años, lo que pudo venir motivado debido a que "El Cuerpo tenía un estatus inamovible, lo cual era bastante desfavorable en un grupo tan cerrado y clasista como era la Armada de esta época"81.

En definitiva, en la estructura de la Armada la consideración venía determinada por la clase profesional a la que se pertenecía, y esta a su vez dependía del estamento de origen que resultaba fundamental para acceder a un tipo de formación determinada. Así, mientras los miembros del Cuerpo General pertenecían a la nobleza (normalmente la baja nobleza), los pertenecientes al Cuerpo de Pilotos de la Armada provenían del tercer estamento. En la fig. 4, se puede ver un ejemplo de la procedencia social de los miembros del Cuerpo de Pilotos de la Armada, reflejada en la profesión paterna en la que se observa que se dedicaban a actividades propias del estado llano, carentes de privilegios, como: contramaestre, calafate, marinero, comercio, mercader, cabo, carpintero y calafate.

Cuando Manuel Sellés y Antonio Lafuente se refieren a la clasificación de los pilotos de la Armada como oficiales de mar y a las quejas y peticiones por ellos realizadas, para situarse a continuación de los de guerra, señalan que las quejas continuaron durante los años "disfrazando, a veces, de científico y profesional un conflicto básicamente estamental" 82 .

\footnotetext{
79 Archivo Naval de Cartagena. Libro1. 878,2. Cuerpo de Pilotos. Pilotos de todas las clases del departamento.

80 Ordenanzas Generales de la Armada. Vol. 1. Madrid: Imprenta de la viuda de Joaquín Ibarra, 1793, pp. $12-13$.

${ }^{81}$ ALÍA PLANA, José Miguel. La enseñanza de la náutica... Op. cit., p. 274.

82 SELLÉS GARCÍA, Manuel y LAFUENTE GARCíA, Antonio. La formación de los pilotos en la España del siglo XVIII. La ciencia moderna y el conocimiento del nuevo mundo. En: PESET REIG,
} 


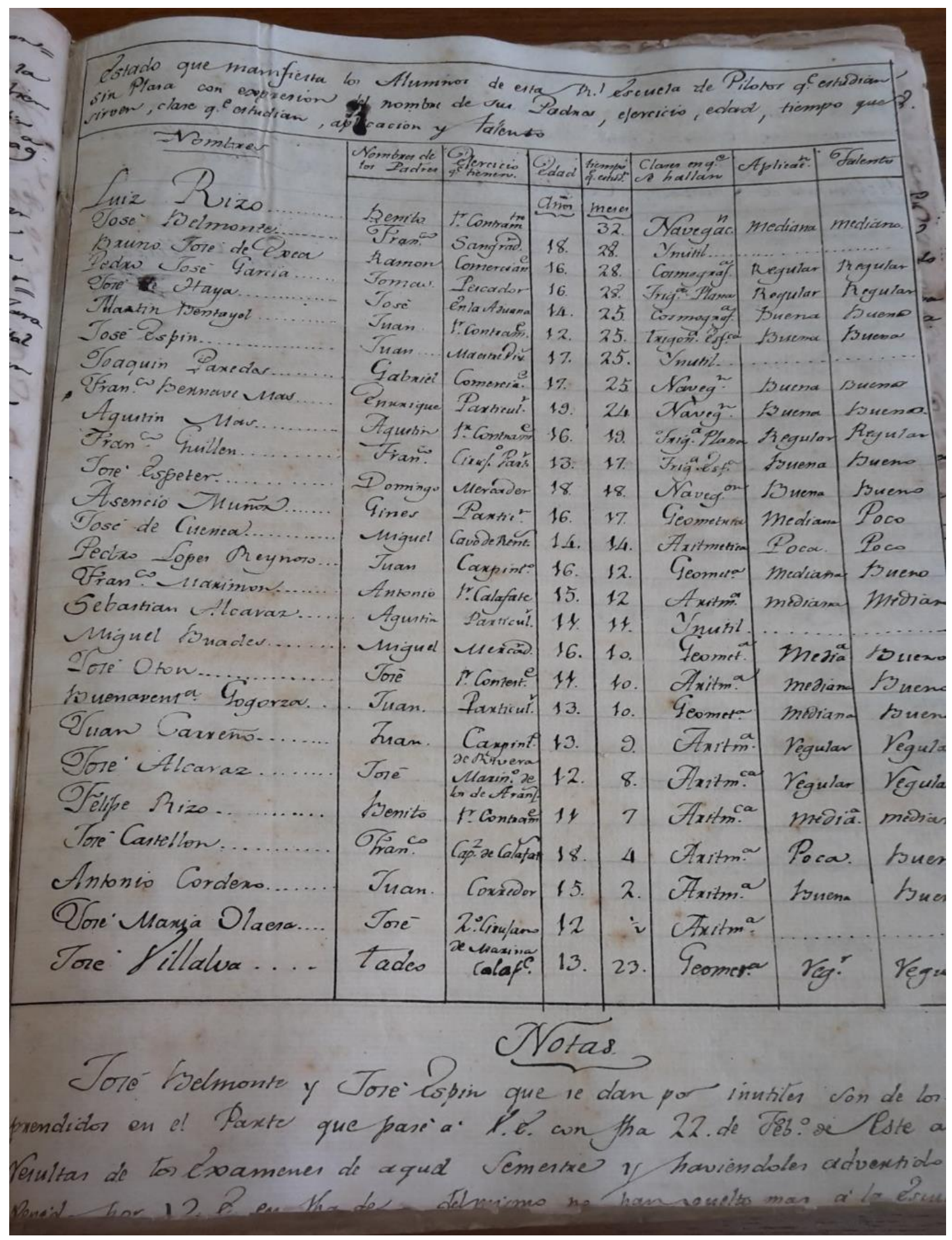

Fig. 4: Estado que manifiestan los alumnos de la Escuela Departamental de Navegación de Cartagena. Fuente: ANC. Caja 886. Libro no 1.

José Luis (coord.). Actas de la I Reunión de Historia de la Ciencia y de la Técnica de los Países Ibéricos e Iberoamericanos. Madrid, del 25 al 28 de septiembre de 1984. Madrid: Consejo Superior de Investigaciones Científicas, 1985, p. 163. 


\section{Consideración del piloto como técnico en la navegación}

Antes del descubrimiento de América, el comercio marítimo estaba limitado al Mediterráneo, al cabotaje y al fluvial. El piloto realizaba la navegación a la vista de la costa, para los cual se necesitaban escasos conocimientos de cosmografía, siendo sus instrumentos la brújula y la sonda. En lo que se refiere a los conocimientos de la gente de mar, en la introducción hemos señalado las características e instrumentos que debían de tener los pilotos, según la enumeración realizada por Raymundo Lulio y Alfonso $\mathrm{X}$ el Sabio. El libro del Saber de Astronomía contenía los conocimientos necesarios para poder obtener la latitud por los astros, quedaba por determinar la longitud, que se resolvería en el siglo XVIII. Estas consideraciones pueden inducir a pensar que estos conocimientos eran comunes a los pilotos de la época; pero parece ser que no era así. Los mareantes era gente dura, pobre e inculta, que sólo sabían alguna regla de pilotaje aprendida en las "conversaciones de puertos", siendo pocos los que eran capaces de entender de forma razonada las reglas del pilotaje y, cuando se refiere a las navegaciones oceánicas que tuvieron que realizar "Fue una experiencia y una técnica nueva con las que tuvo que enfrentarse el piloto, mal preparado para este tipo de navegación de altura"83.

El punto de partida es el de un piloto eminentemente práctico, carente de toda ciencia para el ejercicio de la profesión, que fue evolucionando y de forma gradual se valió de medios técnico-científicos para poder desempeñar su labor de forma eficiente. Esta evolución se inició, como hemos visto, con el nombramiento del piloto mayor, considerado el primer cargo técnico de la Casa de Contratación de Sevilla. A partir de ese momento, para ejercer la profesión se establecerán unos requisitos teórico-prácticos que tuvieron que superar los aspirantes a piloto.

Los propios autores de los Tratados de Navegación (Artes o Regimientos) de los siglos XVI y XVII, fueron los encargados de plasmar en sus textos el estado de la formación y el nivel de preparación que tenían los pilotos de la época. Extremo que también se reflejaba en las Reales Cédulas en las que se establecían los requisitos que debían cumplimentar los pilotos. Entre los textos enumeramos en la tabla 8 los más destacados.

${ }^{83}$ GARCÍA FRANCO, Salvador. Historia del arte... Op. cit., vol. 2, p. 178. 


\begin{tabular}{|l|l|}
\hline \multicolumn{2}{|c|}{ Percepción de los autores de textos náuticos sobre la preparación náutica de los } \\
pilotos
\end{tabular}

Tabla 8: Percepción de los autores de textos náuticos sobre la preparación náutica de los pilotos. Fuente: Elaboración propia.

La literatura de la época también se ocupa de cual era la preparación técnica del piloto, en este sentido, Salazar a raíz de realizar un viaje en 1573 desde Tenerife la Isla la Española de la cual fue nombrado oidor, describe de una forma jocosa en carta escrita al licenciado Miranda de Ron, como los pilotos realizan las observaciones y los diferentes resultados obtenidos, por cada uno, al calcular la situación del buque ${ }^{84}$.

Como vemos, los pilotos, tampoco como técnicos fueron muy bien tratados, se les calificó de inexpertos, incultos, ignorantes, etc.; pero, es indudable que los instrumentos de observación eran rudimentarios, las tablas y cartas inexactas, los conocimientos existentes de astronomía eran los que se estudiaban en el cuadrivio en las Universidades de Salamanca, Oxford y Paris, utilizando el Tractatus Sphaerae (1250) de Juan de Sacrobosco (ca. 1195 - 1256).

Algunos historiadores modernos consideran que los conocimientos de Martín Behaim $(1459-1507)^{85}$ o al menos su práctica no eran superiores a la de los pilotos españoles y portugueses ya que en la expedición que hizo en los 1484-1486 con Diego Cao, por las costas occidentales de Africa, los errores que cometió en el cálculo de la latitud de su esfera terrestre, estuvieron entre $10^{\circ}$ y $16^{\circ}$ "mientras que es sabido que muchas de las observaciones verificadas por dichos pilotos llegan á una exactitud de 2 a 3 grados" 86 . Lo que nos indica que los sistemas de posicionamiento astrónomicos en la mar, tampoco acababan de ser plenamente dominados por los científicos del momento.

\footnotetext{
84 SALAZAR, Eugenio. Cartas de Eugenio de Salazar... Op. cit., pp. 54-55.

85 Martín Behaim, discípulo de Regiomontano (1436 - 1476), junto a Josef Vizinho (fall. 1470) y otros perteneció a la junta de astrónomos y matemáticos, creada por Juan II de Portugal, que según Solís y Sellés en Historia de la ciencia. 4⿳亠丷a ed. Barcelona: Espasa Libros, 2015: "pusieron a punto instrumentos como la ballestilla y tablas astronómicas" (p. 334).

$86 \mathrm{GELCICH}$, Eugen. Estudios sobre el desenvolvimiento histórico de la navegación: especialmente referidos a las ciencias náuticas. Valencia: Librería de pascual Aguilar, 1889, p. 76.
} 
A pesar de su escasa preparación, los pilotos se aventuraron a un mar desconocido, descubriendo nuevas tierras, las posicionaron y dibujaron sus contornos.

Pilotos que incluso fueron capaces de crear nuevas reglas, diseñar instrumentos o de realizar nuevas cartas náuticas, suficientemente precisas, para las nuevas generaciones y para el bien del comercio marítimo y de toda la humanidad. Creemos que mas bien buena parte de la culpa se debe a que los pilotos no estaban lo suficientemente apoyados por la técnica y ciencia de la época, que no fue capaz de desarrollar con la debida rapidez los instrumentos necesarios, ni a proporcionar reglas simples que pudieran ser aplicadas fácilmente por los pilotos, de acuerdo a las necesidades de las nuevas técnicas de navegación ${ }^{87}$.

Francisco de Ruesta, piloto mayor (1638-1673), gran defensor de la gente de mar, escribió en 1669 un discurso sobre "Cualidades de los Pilotos en la Carrera de Indias", en la que señala la ciencia que debe poseer el piloto, en el que acaba añadiendo la descripción del buen piloto que hace Alfonso X el Sabio en las partidas, bajo el epígrafe de Naucheros, descrito así:

En cuanto a las ciencias adquiridas señala 31 ciencias que han de servir de realce a los Pilotos: Philosophia, Phisiologia, Cosmotheoria, Uranologia, Geographia, Hidrographia, Corographia, Topographia, Metheorologia, Atmosphaeralogia, Anemographia, Astrologia Rustica, Astrologia Judiciaria, Magnetologia, Mecometria, Limeneuretica, Hylocimefia, Arithmetica, Geometría, Statica, Hidrostatica, Spartostatica, Troclostatica, Cetrobatica, Sphenostatica, Cocblestatica, Acrobarica, Aerostatica, Pirostatica, Polymechanostatica y Architectura $[\ldots]^{88}$.

Ruesta consideró que el piloto, además de los conocimientos técnicos necesarios para poderse situar en la mar, debía ser poseedor de unos conocimientos en las partes naturales y morales, complementado por unos sólidos conocimientos científicos. En definitiva, procurar que el piloto tuviese una formación humana y científico-técnica, lo más amplia posible. Extremo que se consiguió, paso a paso, a través los diferentes planes de estudio que han conocido estas enseñanzas.

Relacionado con las profesiones del mar Ángel Guirao realiza un interesante estudio, en el que intenta demostrar la inexistencia del profesional del mar durante el periodo de la dinastía de los Austrias, tomando como base las definiciones de profesional y oficio de las cuales extrae cinco características para definir lo que constituye una profesión, a saber:

1. Debe tratarse de una actividad de cuyo ejercicio se derive una gran responsabilidad social.

2. Debe ser independiente de la propiedad.

87 LOUZÁN LAGO, Felipe. Génesis y evolución de los instrumentos de alturas usados en navegación: Análisis de los errores cometidos durante las observaciones [tesis doctoral]. A Coruña: Universidade da Coruña, 2005, p. 585.

88 BERNABEÚ ALBERT, Salvador. Cualidades de los pilotos de la carrera de Indias según el piloto mayor Francisco Ruesta (1669). Revista de Indias. 1986, n. 46, pp. 331-344. 
3. Su ejercicio tiene que descansar en un conjunto de conocimientos sistematizados, es: una disciplina, una ciencia.

4. Es precisa la existencia de un reglamento, bien sea una ley o cualquier otra forma emanada por el Estado, bien sea un código deontológico, de cuyo cumplimiento se ocupan los colegios profesionales, las cofradías, etc.

5. Requiere la existencia de una forma determinada de acceso al ejercicio, a través del aprendizaje de un conjunto de conocimientos, lo que implica un tratamiento pedagógico, y cuyo fin último es la consecución del título ${ }^{89}$.

En base a ese estudio, Ángel Guirao sólo encuentra uno que las cumpla todas, el piloto, calificándolo como único profesional del mar entre todos los órganos ${ }^{90}$ que formaban a lo largo de los siglos XVI y XVII las diferentes Armadas y Escuadras.

Los conocimientos de los pilotos tuvieron que adaptarse a las necesidades que la navegación marítima iba planteando. Cuando las naves se alejaban de la costa, se recurría a la observación de la altura de la Estrella Polar y la del Sol al mediodía, para obtener la latitud geográfica. Para ello, los pilotos tuvieron que saber construir y utilizar el astrolabio, el cuadrante y la ballestilla, así como usar las tablas de las declinaciones del Sol y hacer los cálculos necesarios siguiendo los regimientos del Sol y de la Polar. Se pasó de la navegación de fantasía (rumbo y distancia), a la de escuadría (latitud observada y rumbo), para desembocar en el siglo XVIII en la navegación científica, en la que en la formación del piloto se potenció el conocimiento de las matemáticas y la aplicación de los nuevos métodos del cálculo de la longitud por las distancias lunares y el cronómetro.

\section{Conclusiones}

Durante la Edad Moderna dos organismos intervinieron directamente en la reglamentación profesional del piloto: la Casa de Contratación (1508-1748) y la Armada (1748 - se extendió más allá del periodo que abarca este trabajo), pivotando sobre tres hechos fundamentales, la creación del cargo de piloto mayor de la Casa de Contratación de Sevilla (1508), la creación del Cuerpo de Pilotos de la Armada (1748) y la promulgación del Plan Winthuysen (1790), constituyendo dos etapas, la primera que denominamos de consolidación va desde 1508-1748 y la segunda de militarización va de $1748-1790$.

A lo largo de los 240 años que duró la primera etapa se consolidó la profesión de piloto, tanto en el ámbito académico como en el profesional quedó establecido el periodo de formación que tenían que cumplimetar, los exámenes a realizar y la obligatoriedad de disponer del título correspondiente para poder acceder a la profesión. En lo social, a pesar de los muchos intentos que se hicieron, sobre todo, desde la Universidad de Mareantes para conseguir derechos para los pilotos, poco se avanzó

\footnotetext{
89 GUIRAO DE VIERNA, Ángel. El Profesional del mar, reclutamiento, nivel social, formación. En: I Jornadas de Historia Marítima. España y el Ultramar hispánico hasta la llustración. Madrid: Instituto de Historia y Cultura Naval, pp. 97-112, p.102.

90 Siendo estos: "[...] de asistencia a la decisión - los altos mandos-, - de asistencia operativa-, -los mandos de agrupación-, -administrativos-, - veedor, contador, proveedor, etc.- jurisdiccionales-, auditor, escribano, etc.-, -y de asistencia técnica y servicios-, capellán, cirujano, piloto, comitre, maestre, etc". GUIRAO DE VIERNA, Ángel. El Profesional del mar... Op. cit., p.103.
} 
en ese terreno, por lo que en el ámbito social fue una etapa de tímidos avances. A oír la Cátedra de Navegación seguían acudiendo aquellos que anteriormente habían navegado como marineros y el Colegio de San Telmo de Sevilla seguía recogiendo a niños pobres para formarlos en la profesión marinera.

La segunda etapa se inicia a través de las OGA, 1748, en la que se creó el Cuerpo de Pilotos de la Armada para que ésta tuviese sus propios pilotos, extendiendo su reglamentación a los pilotos particulares, lo que supuso un cambio de paradigma, con una concepción totalmente diferente del piloto quedando supeditado a la Marina de guerra, en los ámbitos académico y profesional. Aunque los pilotos de la Armada compartieron la denominación de "pilotos" con los de la Carrera de Indias y los de las flotas particulares, en principio, la finalidad de su instrucción era diferente. Mientras a estos últimos se les preparaba para dirigir el buque, a los primeros únicamente se les preparó para ser técnicos de la navegación, siendo encuadrados en su origen, dentro del grupo de 'oficiales de mar', considerado este un nivel subalterno en el organigrama de la Armada. Esto es, en la cadena de mando a bordo de los buques de la Armada se situó a los pilotos por debajo incluso de los guardiamarinas, que eran alumnos aspirantes a oficiales de marina, esta clasificación jerárquica no varió a pesar de que mediante las OGA, 1793 los pilotos pasaron a ser considerados oficiales mayores. Con la promulgación de las OGA, 1748 la Armada inicio un proceso tendente a imponer un modelo de piloto vinculado y supeditado a la Armada mediante el diseño de sus planes de estudio, realización de exámenes profesionales y la organización de las Escuelas de Náutica, que culminó con el plan Winthuysen (1790), dicha supeditación se extendió más allá del periodo de estudio que abarca este trabajo.

El estamento social de origen actuó como una barrera infranqueable y un lastre del que no pudieron deshacerse los pilotos y les persiguió durante toda la época que abarca este estudio, normalmente no tuvieron acceso a los mandos superiores de las flotas, a la vez que vieron limitado su desarrollo técnico y profesional. En definitiva, los pilotos fueron damnificados por la Administración bajo los Austrias y los Borbones, fundamentalmente por la escala social de la que provenían y aún hoy en día, su figura continua difuminada en la historia, como es patente en la mayoría de los casos, en las que se les denomina con el genérico de marino, cosmógrafo o por su graduación militar aquellos que la tuvieron, ignorando su condición de piloto.

\section{Bibliografía}

ALÍA PLANA, José Miguel. La enseñanza de la náutica en la Armada Española (1717-1820) [tesis doctoral]. Madrid: Universidad Nacional de Educación a Distancia, 2001, pp. 274-276.

Anónimo. Recopilación de las leyes de los Reinos de las Indias, mandada imprimir y publicar por la Magestad Católica del Rey Don Carlos II, Nuestro Señor. Vol. III. Madrid: Boix, 1841, p. 305.

BARRAS DE ARAGÓN, Francisco de las. Circunstancias que motivaron la fundación del Colegio de San Telmo de Sevilla. Madrid: Asociación Nacional de Historiadores de la Ciencia Española, 1935. 
BLANCA CARLIER, José María. El cuerpo de pilotos de la Armada. Revista General de Marina. 1979, n. 197, pp. 165-173.

BERNABEÚ ALBERT, Salvador. Cualidades de los pilotos de la carrera de Indias según el piloto mayor Francisco Ruesta (1669). Revista de Indias. 1986, n. 46, pp. 331-344.

CAPMANY Y DE MONPALAU, Antonio. Código de las costumbres marítimas de Barcelona, hasta aquí vulgarmente llamado libro del consulado. Madrid: Imprenta de Don Antonio Sancha, 1791, pp. 32-33.

CARAVACA DE COCA, José María. Apuntes para la historia de la Academia de la Real compañía de Guardias Marinas en sus momentos iniciales en Cádiz como continuadora de la labor científica de la Casa de la Contratación. Revista General de Marina. 2015, n. 269, pp. 877-891.

CÉSPEDES DEL CASTILLO, Guillermo. La defensa de América. En: RUIZ MARTíN, F. La monarquía de Felipe II. Madrid: Real Academia de la Historia, 2003, pp. 381-412.

CHAUNU, Pierre. La Expansión Europea (siglos XII al XV). Barcelona: Labor, 1977, p. 220.

CORONA BARATECH, Carlos E. y ARMILLAS VICENTE, José Antonio. Historia General de España y América: La España de las Reformas Hasta el final del Reinado de Carlos IV. Volumen 10-2. Madrid: Rialp, 1990.

DELGADO Y ORELLANA, José Antonio. Catálogo de pruebas de nobleza del Real Colegio de San Telmo de Sevilla. Madrid: Hidalguía, 1985.

Enciclopedia General del Mar. Barcelona: Ediciones Garriga, 1992, p. 1.267.

ESCALANTE DE MENDOZA, Juan. Itinerario de navegación. Madrid: Museo Naval (1985), 1575, p. 56.

FERNÁNDEZ ALMAGRO, Melchor. Política naval de la Edad Moderna y Contemporánea. Madrid: Instituto de estudios políticos, 1946, p. 30.

FERNÁNDEZ DE NAVARRETE, Martín. Colección de los viages y descubrimientos que hicieron por mar los españoles desde fines del siglo XV. Vol. 3. Madrid: Imprenta Real, 1829.

FERNÁNDEZ DURO, Cesáreo. Disquisiciones Náuticas. La Mar descrita por los mareados. Vol. 4. Madrid: Impresores de Cámara de S.M, 1877.

FERNÁNDEZ DURO, Cesáreo. Disquisiciones Náuticas. Los ojos en el cielo. Vol. 4. Madrid: Impresores de Cámara de S.M., 1879.

FERNÁNDEZ DURO, Cesáreo. Disquisiciones Náuticas. Arca de Noé. Vol. 6. 
Madrid: Imprenta, Estereotipia y Galvanoplastia de Aribau y C. Sucesores de Rivadeneyra, 1881.

GARCIA DE PALACIO, Diego. Instrucción náutica, para el buen uso, y regimiento de las naos, su traza, y gobierno conforme a la altura de México. México: En casa de Pedro Ocharte, 1587, fol. 151.

GARCÍA FRANCO, Salvador. Historia del arte y ciencia de navegar. Desenvolvimiento histórico de los cuatro términos de la navegación. Vol. 2. Madrid: Instituto histórico de Marina, 1947, p. 177.

GARCÍA GARRALÓN, Marta. Taller de mareantes. El Real Colegio Seminario de San Telmo de Sevilla (1681-1847). Vol. 2. Sevilla: Cajasol Obra Social, 2007, pp. 160-167.

GARCÍA GARRALÓN, Marta. Los ojos del buque. Los pilotos de los navíos del Rey (1748-1846). En: SÁNCHEZ BAENA, Juan José; CHAÍN NAVARRO, Celia y MARTÍNEZ SOLÍS, Lorena (coords.). Estudios de Historia Naval. Actitudes y medios en la Real Armada del s. XVIII. Madrid: Ministerio de Defensa; Murcia: Universidad de Murcia, Editum, 2011, pp. 189-213.

GARCÍA GARROSA, María Jesús. La Real Cédula de 1783 y el teatro de la ilustración. Bulletin Hispanique. 1993, vol. 95, n. 2, pp. 673-692.

GELCICH, Eugen. Estudios sobre el desenvolvimiento histórico de la navegación: especialmente referidos a las ciencias náuticas. Valencia: Librería de pascual Aguilar, 1889, p. 76.

GOODMAN, David. El poderío naval español: Historia de la armada española en el siglo XVII. Barcelona: Península, 2001, p. 315.

GUIRAO DE VIERNA, Ángel. El Profesional del mar, reclutamiento, nivel social, formación. En: I Jornadas de Historia Marítima. España y el Ultramar hispánico hasta la Ilustración. Madrid: Instituto de Historia y Cultura Naval, pp. 97-112, p.102.

JIMÉNEZ JIMÉNEZ, Elisa María. El Real Colegio Seminario de San Telmo de Sevilla (1681-1808). Sevilla: Universidad de Sevilla, 2002.

LÓPEZ, Gregorio. Las siete partidas del Rey Don Alfonso el Sabio. Cotejada por el Lic. Gregorio López. Vol. 2. Segunda y Tercera partida. París: Lecointe y Laserre, 1843, p. 285.

LÓPEZ PIÑERO, José María. Ciencia y técnica en la sociedad española de los siglos XVI y XVII. Barcelona: Labor, 1979, p. 52.

LÓPEZ PIÑERO, José María. El Arte de Navegar en la España del Renacimiento. Barcelona: Labor, 1986, p. 128. 
LOUZÁN LAGO, Felipe. Génesis y evolución de los instrumentos de alturas usados en navegación: Análisis de los errores cometidos durante las observaciones [tesis doctoral]. A Coruña: Universidade da Coruña, 2005, p. 585.

LULL, Ramón. Arbol de la ciencia de el muy iluminado maestro Raymvndo Lvlio: nuevamente traducido y explicado por el Teniente de Maestro de Campo General Don Alonso de Zepeda y Adrada, Governador de el Thol-huys. Bruselas: Francisco Foppens, Impresor y mercader de libros, 1663, p.100.

LYRA, Francisco de. Ordenanzas Reales para la Casa de Contratación de Sevilla y para otras cofas de las Indias, y de la navegación, y contratación de ellas. Sevilla, 1647.

MARCOS MARTÍN, Alberto. España en los siglos XVI, XVII y y XVIII. Barcelona: Crítica, 2000.

MARTÍN GARCÍA, Alfredo. Entre el mar y la muerte. Procedencias, condiciones de vida y mortalidad de los navegantes en el Real Servicio (1776-1804). Espacio, Tiempo y Forma, Serie IV, Hª . Moderna. 1999, n. 12, pp. 415-441.

MARTÍN-MERÁS, Luisa. Las enseñanzas náuticas en la Casa de la Contratación de Sevilla. En: ACOSTA, A.; GONZÁLEZ, A. y VILA, E. (coords.). La Casa de la Contratación y la navegación entre España y las Indias. Sevilla: Universidad de Sevilla; CSIC; Fundación el Monte, 2004, pp. 667-693.

MEDINA, José Toribio. El Veneciano Sebastián Caboto al servicio de España. Vol. 1: Texto. Santiago de Chile: Imprenta y Encuadernación Universitaria, 1908.

MIRA CABALLOS, Esteban. La vida y muerte a bordo de un navío del siglo XVI: Algunos aportes. Revista de la Historia Naval. 2010, n. 108, pp. 39-57.

NAVARRO GARCÍA, Luis. Pilotos, maestres y señores de naos en la carrera de las Indias. Revista histórica, literaria y artística. 1967, vol. 46, n. 141, pp. 241-298.

Ordenanzas Generales de la Armada. Vol. 1. Madrid: Imprenta de Juan Zuñigam, 1748.

Ordenanzas para el Real Colegio de San Telmo de Sevilla. Madrid: Imprenta de la Viuda de lbarra, 1786.

Ordenanzas Generales de la Armada. Vol. 1. Madrid: Imprenta de la viuda de Joaquín Ibarra, 1793, pp. 12-13.

PÉREZ-MALLAínA BUENO, Pablo Emilio. Los Hombres del Océano. Vida cotidiana de los tripulantes de las flotas de Indias. Siglo XVI. Sevilla: Servicio de Publicaciones de la Diputación de Sevilla, 1992, p. 36.

PÉREZ-MALLAíNA BUENO, Pablo Emilio. La Creación de la Universidad de Mareantes. Cuadernos monográficos del Instituto de Historia y Cultura Naval. 
2001, n. 43-62, p. 49.

PÉREZ-MALLAÍNA BUENO, Pablo Emilio. Naufragios en la Carrera de Indias durante los siglos XVI y XVII. El hombre frente al mar. Sevilla: Universidad de Sevilla, 2015.

PONS I GURI, Josep María. Estudi dels Pilots: Assaig monogràfic sobre la Reial Escola de Nàutica d'Arenys de Mar. Barcelona: Curial Edicions Catalanes, 1993.

PULIDO RUBIO, José. El Piloto Mayor de la casa de Contratación de Sevilla. Pilotos mayores, catedráticos de cosmografía y cosmógrafos. Sevilla: Escuela de Estudios Hispano Americanos, 1950.

REBOLLO ESPINOSA, María José. Desprestigio social y oficios viles en la España del siglo XVIII. Ascendencia socio profesional del alumnado del Real Colegio Seminario de San Telmo de Sevilla. Cuestiones pedagógicas. 1988, n. 45, pp. 211-227.

Reglamento general de quanto abraza el total armamento de los navios, fragatas y corbetas de la Real Armada, desde la manga de 29 codos hasta la de 14. Santiago: Ignacio Aguayo y Aldemunde, 1792.

RODRÍGUEZ CANCHO, Miguel. Cambios y tensiones sociales en el siglo XVII. En: FLORISTÁN, A. Historia moderna universal. Barcelona: Editorial Planeta, 2016, pp. 515-528.

RODRÍGUEZ-MARTOS I DAHUER, Ricardo. El buque mercante un análisis sociológico. Barcelona: UPC, 1996.

SALAVERT FABIANI, Vicent Lluis. La cultura científico técnica en la España de los siglos XVI y XVII. Bulletin Hispanique. 1995, vol. 97, n. 1, pp. 233-259.

SALAZAR, Eugenio. Cartas de Eugenio de Salazar, vecino y natural de Madrid, escritas à muy particulares amigos suyos, publicadas por la sociedad de bibliófilos españoles. Madrid: Imprenta y Esterotipia de M. Rivadeneyra, 1573 (edición 1866).

SELLÉS GARCÍA, Manuel y LAFUENTE GARCÍA, Antonio. La formación de los pilotos en la España del siglo XVIII. La ciencia moderna y el conocimiento del nuevo mundo. En: PESET REIG, José Luis (coord.). Actas de la I Reunión de Historia de la Ciencia y de la Técnica de los Países lbéricos e Iberoamericanos. Madrid, del 25 al 28 de septiembre de 1984. Madrid: Consejo Superior de Investigaciones Científicas, 1985, pp. 149-192.

SOLÍS, Carlos y SELLÉS, Manuel. Historia de la ciencia. 4aㅡ ed. Barcelona: Espasa Libros, 2015.

Tomo segundo de las leyes de recopilación que contienen los libros sexto, septimo, octavo y nono. Madrid: Herederos de la viuda de Juan García Infanzón, 1745. 
TORRE, Tomás de la (Fray). Diario de viaje de Salamanca a Ciudad Real de Chiapa, 1544-1545. Caleruega (Burgos): OPE, 1985.

VEITIA LINAJE, José. Norte de la Casa de Contratación de las Indias Occidentales. Sevilla: Juan Francisco de Blas, 1672.

VICENS VIVES, Jaume. Historia Económica de España. Barcelona: Vicens-Vives, 1977.

VIGIER DE TORRES, Agustín. Curso de Derecho Marítimo. Madrid: Subsecretaría de la Marina Mercante, 1969, p. 449. 